\title{
Bivalves límnicos da bacia do rio dos Sinos, Rio Grande do Sul, Brasil (Bivalvia, Unionoida, Veneroida e Mytiloida)
}

\author{
Maria C. D. Mansur ${ }^{1} \&$ Daniel Pereira ${ }^{2}$ \\ ${ }^{1}$ Coordenação de Ensino de Pós-Graduação, Reitoria, Universidade Federal de Mato Grosso. Avenida Fernando Correa da \\ Costa, 78060-900 Cuiabá, Mato Grosso, Brasil. E-mail: maria.mansur@pucrs.br \\ ${ }^{2}$ Laboratório de Aquacultura, Setor de Malacologia, Museu de Ciência e Tecnologia, Pontifícia Universidade Católica do Rio \\ Grande do Sul. Caixa-Postal 1429, Avenida Ipiranga 6681, 90619-900 Porto Alegre, Rio Grande do Sul, Brasil. \\ E-mail: daniel@grupolimnoperna.com
}

\begin{abstract}
Limnic bivalves of the Sinos river basin, Rio Grande do Sul, Brazil (Bivalvia, Unionoida, Veneroida And Mytiloida). Ten species of Hyriidae, ten of Mycetopodidae, three of Corbiculidae - two exotic: Corbicula Iargillierti (Philippi, 1844) and C. fluminea (Müller, 1774) -, three Sphaeriidae and one exotic Mytilidae, Limnoperna fortunei (Dunker, 1857), were taxonomically revised with diagnosis and identification key for the Sinos River Basin, State of Rio Grande do Sul, Brazil. Voucher specimens of several scientific collections were examined. The type locality of Anodontites iheringi (Clessin, 1882) is presently restricted to Paranhana River, Municipality of Igrejinha (29 $36^{\prime}$ 'S and $\left.50^{\circ} 50^{\prime} \mathrm{W}\right)$. Species distribution according to the river zones (high, middle and low) is presented. KEY WORDS. Freshwater mussels; Subtropical River; South Brazil; survey; taxonomy.
\end{abstract}

RESUMO. Com base no exame de exemplares de moluscos bivalves depositados em várias coleções científicas locais e internacionais, procedentes da bacia do rio dos Sinos, estado do Rio Grande do Sul, Brasil, apresentouse uma revisão taxomica com diagnoses e chave dicotômica. Registram-se dez espécies de Hyriidae, dez de Mycetopodidae, três de Corbiculidae - duas exóticas: Corbicula largillierti (Philippi, 1844) e C. fluminea (Müller, 1774) -, três de Sphaeriidae e uma exótica de Mytilidae, Limnoperna fortunei (Dunker 1857). Restringiu-se a localidade tipo de Anodontites iheringi (Clessin, 1882) ao rio Paranhana, no município de Igrejinha (29³6'S e 5050’ W). As espécies foram distribuidas de acordo com as diferentes zonas do rio (superior, média e inferior).

PALAVRAS-CHAVE. Inventário; moluscos bivalves; rio subtropical; sul do Brasil; taxonomia.

A bacia do rio dos Sinos corresponde $4,5 \%$ da bacia hidrográfica do lago Guaíba, que é formada pelos rios Gravataí, dos Sinos, Caí, e Jacuí. O rio dos Sinos (extensão aproximada de 190 km) nasce ao norte, no município de Santo Antônio da Patrulha a uma altitude de $600 \mathrm{~m}$ e corre em direção sul, desaguando no delta do Jacuí (Comıtesinos 1990). As citações mais antigas de moluscos para a bacia do rio dos Sinos datam do final do século XIX. Compreendem material coletado pelo Dr. Reinold Hensel e pelo Dr. Hermannn von Ihering em suas visitas às colônias de origem alemã localizadas principalmente nos municípios de Taquara e São Leopoldo, adjacentes ao rio dos Sinos e seu afluente principal, o rio Santa Maria, atualmente denominado rio Paranhana (Hensel 1867, Martens 1868, Clessin 1882, 1888). Os moluscos coletados por Hensel foram enviados para o naturalista Ed. von Martens, que identificou e descreveu espécies novas que se encontram depositadas no Zoologisches Museum der Humboldt Universität (ZMHU), em Berlim. O material recoIhido por Ihering foi enviado em parte ao seu amigo S. Clessin, do Stuttgart Museum für Naturgeschichte (SMNS), em Stuttgart e também para outros museus. Segundo informação do Geólogo
H. J. Niederhofer, atual curador da coleção de moluscos do SMNS, o material de Clessin deveria estar todo depositado na coleção daquele Museu que foi destruído, em grande parte, na segunda guerra mundial.

H. von Ihering, médico clínico geral e naturalista, mudou-se para o Brasil (Rio de Janeiro) em 1880, aos 30 anos de idade. Posteriormente transferiu-se para o Rio Grande do Sul, onde residiu, até 1892, em uma ilha do delta do rio Camaquã (VAZ 1986). Ao visitar pacientes nas colônias alemãs e na passagem por Porto Alegre, coletou moluscos de água-doce. O material obtido foi citado e ou descrito como espécies novas, em sua vasta obra sobre moluscos (IHERING 1893, 1910, 1923). Grande parte deste material encontra-se depositado no Senckenberg Museum (SBMF), em Frankfurt junto ao Meno, Alemanha, no National Museum of Natural History (NMNH), Washington, EUA e no Natural History Museum (BMNH), Londres, Inglaterra. Posteriormente, grande parte do material de lhering foi revisado por HAAS (1930, 1931a, b, 1969) e por PAROdIz (1968, 1973). Parte dos exemplares, inclusive de Sphaeriidae, também foram depositados por $\mathrm{H}$. von Ihering no Museu Paulista (atu-

Revista Brasileira de Zoologia 23 (4): 1123-1147, dezembro 2006 
al Museu de Zoologia da Universidade de São Paulo - MZUSP), São Paulo, cuja direção assumiu no período 1894-1916. Os exemplares de Corbiculidae coletados em São Leopoldo (Rio Grande do Sul) foram enviados por $\mathrm{H}$. von Ihering ao $\mathrm{NMNH}$, onde foram depositados.

O antigo Colégio de Nossa Senhora da Conceição, que alojava o Museu de História Natural, em São Leopoldo, Rio Grande do Sul, originou a Universidade do Vale do Rio dos Sinos (UNISINOS). Este Museu possuia coleções científicas de fauna de valor imensurável e, no ano de 1981, todo material foi destruido em um incêndio. Em meados da década de 1980, o ornitólogo Martin Sander realizou expedições científicas periódicas com alunos das disciplinas de Zoologia, do curso de Ciências Biológicas, da UNISINOS, aos banhados da planície de inundação do rio dos Sinos, incorporando vasto material malacológico límnico à nova coleção científica que originou o atual Museu de Zoologia da UNISINOS (MZU), constituindo-se numa das mais representativas coleções de moluscos para a bacia do rio dos Sinos, no Brasil.

Mansur (1970) compilou todos os registros de bivalves Hyriidae e Mycetopodiidae para o Roi Grande do Sul e Bonetro \& MANSUR (1970) realizaram o levantamento dos moluscos bivalves da bacia do lago Guaíba. Com base em material coletado no arroio Manteiga, afluente do rio dos Sinos, VeITENHEIMERMendes \& Mansur (1978a, b) e Mansur \& Veitenheimer-Mendes (1979) realizaram estudos sobre Mycetopoda legumen (Martens, 1868), enfocando aspectos biológicos e a redescrição da espécie.

Objetiva-se apresentar uma chave dicotômica para espécies e níveis supraespecíficos, uma revisão taxonômica, com diagnose, redefinição de formas e contornos da concha, ilustrações e distribuição das espécies de bivalves de água-doce, conforme as zonas do alto, médio e baixo rio dos Sinos, com o intuito de contribuir para inventários malacofaunísticos, uma vez que grande parte das espécies de bivalves, descritas e citadas para as bacias do sul do Brasil, são pouco conhecidas. Este trabal ho também visa homenagear e dar continuidade ao trabalho de campo e literário descritivo iniciado por Hermannn von Ihering, que se destacou pela contribuição científica ímpar ao conhecimento da malacologia no Rio Grande do Sul, especial mente nas bacias dos rios Camaquã e dos Sinos.

\section{MATERIAL E MÉTODOS}

Foram revisadas conchas de bivalves depositados nas seguintes coleções científicas: coleção particular Felipe do Canto Quadros (FCQ), Porto Alegre; Carnegie Museum of Natural History (CMNH), Pittsburg; Natural History Museum (BMNH), Londres; Museu de Ciências Naturais Fundação Zoobotânica do Rio Grande do Sul (MCN), Porto Alegre; Museu de Ciências e Tecnologia, Pontifícia Universidade Católica do Rio Grande do Sul (MCP), Porto Alegre; Musée d'Histoire Naturelle Genève (MHNG), Genebra; MZU; MZUSP; Musée d'Histoire Naturelle de Bâle (MHNB), Basiléia; NMNH; SMNS; SBMF; United States National Museum (USNM), Washington; ZMHU e Zoologische
Staatssammlung (ZS), Munique. A bacia do rio dos Sinos foi dividida em zona superior, média e inferior (Fig. 1).

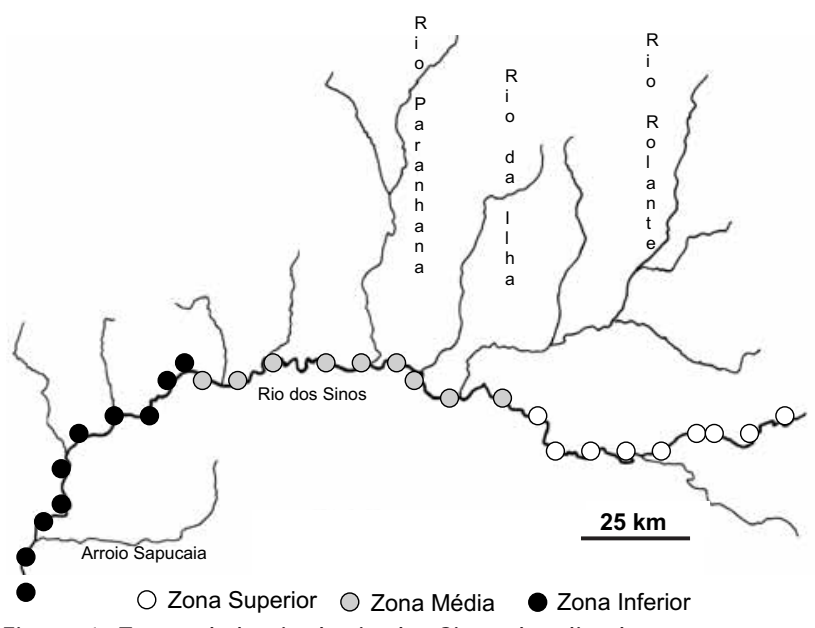

Figura 1. Zonas da bacia do rio dos Sinos, localizada entre as coordenadas $51^{\circ} 20^{\prime}-50^{\circ} 10^{\prime} \mathrm{S}$ e $29^{\circ} 15^{\prime}-30^{\circ} 00^{\prime} \mathrm{W}$, Rio Grande do Sul, Brasil. Adaptado de Comitesinos (1990).

Os exemplares de Pisidium (Sphaeriidae) foram fotografados ao microscópio el etrônico de varredura, modelo Phillips XL30, do Centro de Microscopia e Microanálise da Pontifícia Universidade Católica do Rio Grande do Sul. As conchas foram lavadas com água destilada e secas à temperatura ambiente. As peças foram fixadas sobre "stubs" com auxílio de fita adesiva em dupla face e cola de prata e metalizadas com pó de ouro.

A orientação das valvas, as medidas da concha e a terminologia utilizada seguem em parte MANSUR et al. (1987). A nomenclatura das formas dos bivalves com base no contorno da concha, utilizadas na chave e nas diagnoses, consta no tabela I. Na diagnose são fornecidas medidas de altura e comprimento máximos da concha obtidos dos maiores exemplares examinados.

As espécies foram determinadas por comparação com o material tipo ou topotipos e material adicional examinado das coleções científicas. Para a identificação das espécies dos gêneros Pisidium C. Pfeiffer, 1821, Corbicula Mergele von Mühlfeld, 1811, Cyanocyclas Blainville, 1818, Limnoperna Rochebrune, 1882, utilizaram-se os trabalhos revisivos e ou ilustrações das descrições originais, quando disponíveis. A sinonimia para cada espécie, reune apenas as citações efetivadas para a bacia do rio dos Sinos e trabalhos revisivos de importância para cada táxon abordado.

\section{RESULTADOS E DISCUSSÃO}

Foram inventariadas vinte e sete espécies de moluscos bivalves: dez de Hyriidae, dez de Mycetopodiidae, uma espécie nativa e duas exóticas de Corbiculidae, três de Sphaeriidae e uma exótica de Mytilidae (Tab. II, Fig. 1).

Revista Brasileira de Zoologia 23 (4): 1123-1147, dezembro 2006 
Tabela I. Nomenclatura das formas com base nos contornos dos bivalves.

\begin{tabular}{|c|c|c|c|c|}
\hline \multicolumn{2}{|c|}{ Nomenclatura das formas } & \multirow[t]{2}{*}{ Definição } & \multirow[t]{2}{*}{ Forma } & \multirow[t]{2}{*}{ Exemplo } \\
\hline Básica & Derivada & & & \\
\hline Discóide & & Semelhante a uma circunferência & & \\
\hline Oval & & $\begin{array}{l}\text { Semelhante a um ovo com dois eixos } \\
\text { de simetria }\end{array}$ & & \\
\hline Ovóide & & $\begin{array}{l}\text { Semelhante a um ovo com um eixo } \\
\text { de simetria }\end{array}$ & & \\
\hline Elíptico & & Semelhante a uma elipse & & \\
\hline & Lanceolado & $\begin{array}{l}\text { Semelhante a uma elipse irregular } \\
\text { com a extremidade posterior afilada }\end{array}$ & & \\
\hline & Ovalado & $\begin{array}{l}\text { Semelhante a uma elipse com } \\
\text { contorno ovalado }\end{array}$ & & \\
\hline & Retangulóide & $\begin{array}{l}\text { Semelhante a uma elipse irregular } \\
\text { com bordas quase paralelas } \\
\text { asssemelhando-se a um retângulo }\end{array}$ & & \\
\hline & Rombóide & $\begin{array}{l}\text { Semelhante a uma elipse com bordas } \\
\text { paralelas como um polígono } \\
\text { paralelogramo (com quatro lados } \\
\text { iguais e paralelos) }\end{array}$ & & \\
\hline & Reniforme & $\begin{array}{l}\text { Semelhante a uma elipse irregular } \\
\text { com deflexão ventral }\end{array}$ & & \\
\hline Triangular & & Semelhante a um triângulo & & \\
\hline & Equilateral & $\begin{array}{l}\text { Semelhante a um triângulo } \\
\text { eqüilátero }\end{array}$ & & \\
\hline & Retangulóide & Semelhante a um triângulo retângulo & & \\
\hline Trapézóide & & Semelhante a um trapezóide & & \\
\hline
\end{tabular}


Tabela II. Moluscos bivalves registrados para a bacia do rio dos Sinos, Rio Grande do Sul.

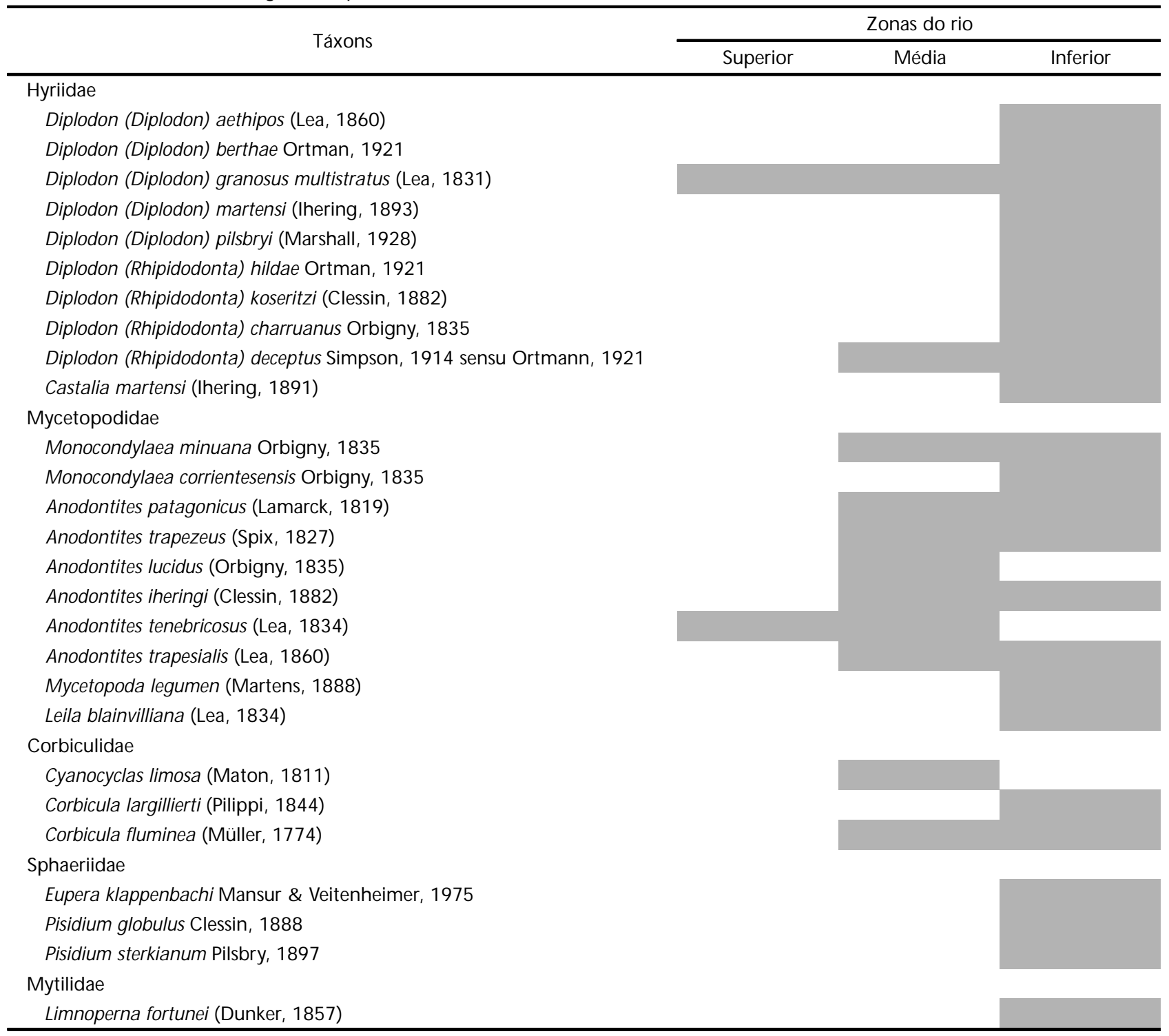

Chave de identificação de bivalves da bacia do Rio dos Sinos

1. Concha de forma mitilóide, triangular retangulóide, umbos situados junto ao limite anterior da concha, carena saliente, charneira edêntula, fixa-se ao substrato por bisso formando aglomerados (Mytiloida, Mytilidae) ... Limnoperna fortunei

1'. Forma não mitilóidevariável (discóide, oval, ovóide, elíptica, triangular eqüilateral ou trapezóide), umbos não situados no limite anterior da concha, geralmente sem bisso e não formam aglomerados .. 2

2. Dentição esquizodonte (charneira com um ou mais dentes pseudocardinais anteriores e um ou dois laterais al ongados posteriores) ou sem dentes

Unionoida

3

$2^{\prime}$. Dentição heterodonte (charneira com dentes cardinais no centro, abaixo dos umbos, elaterais anteriores e posteriores aos umbos). Veneroida ........... 4

3. Charneira sem dentes ou com um ou dois dentes sob os umbos Mycetopodidae 5

3'. Charneira com dentes sob os umbos e laterais alongados atrás dos umbos. Hyriidae ........... 6

4. Forma triangular equilateral, charneira com dentes laterais alongados e serreados Corbiculidae ........... 7

Revista Brasileira de Zoologia 23 (4): 1123-1147, dezembro 2006 
4'. Formas discóides, ovais ou ovóides, charneira com dentes laterais lisos ou com grânulos microscópicos.....

.. Sphaeriidae.

5. Com sínus palial presente Leila blainvilliana

5'. Sem sínus palial ... 9

6. Forma triangular eqüilateral, com carena saliente . Castalia martensi

6'. Forma variável (oval, ovóide ou elíptico), sem carena ou com carena muito baixa e arredondada...Diplodon ....... 10

7. Com sínus palial, superfície externa sem estrias concêntricas salientes Cyanocyclas limosa

7'. Sem sínus palial, superfície externa com estrias concêntricas salientes . Corbicula ......... 19

8. Forma variável (discóide ou oval), com pintas pretas ou marrom na superfície interna da concha (geralmente vistas por fora por transparência) ................. Eupera klappenbachi

8'. Forma variável (discóide, ovóide ou oval), sem pintas pretas ou marrom Pisidium ........ 20

9. Charneira com um dente nacarado em forma de calo, em cada valva Monocondylaea .. 21

9'. Charneira sem dentes .. 22

10. Forma predominantemente discóide, às vezes ovóide, dente pseudocardinal posterior direito robusto muito lascado ..

.. Diplodon deceptus

10'. Forma variável (oval, ovóide a elíptica), dente pseudocardinal posterior direito com poucas lascas, ou lamelar .. 11

11. Forma oval ou ovóide ............................................. 12

11 . Forma elíptica ........................................................... 14

12. Forma oval, borda ventral e dorsal regularmente abaulada, extremidades anterior e posterior na metade da al tura, dente pseudocardinal posterior direito lamelar, perióstraco castanho brilhante Diplodon hildae

12'. Forma ovóide, borda ventral quase reta, borda posterior muito abaulada, dente pseudocardinal posterior direito curto de contorno triangular com aspecto desgastado, perióstraco castanho amarelado sem brilho

. Diplodon granosus multistriatus

14. Forma elíptica-rombóide ou retangulóide .................... 15

14'. Forma elíptica-ovalada ............................................. 16

15. Forna elíptica-rombóide, às vezes elíptica-lanceolada, impressão dos músculos adutores anteriores muito grandes e bem demarcadas, perióstraco negro brilhante às vezes esverdeado Diplodon aethiops

15'. Forma elíptica-retangulóide, perióstraco castanho com brilho seroso, impressão dos músculos adutores anteriores pequenas Diplodon martensi

16. Borda dorsal muito abaulada, a ventral mais abaulada após a metade posterior concha, depressão interna oblíqua que parte da cavidade sub-umbonal em direção a região pósteroventral da concha como se cada valva fosse internamente pressionado pelo dedo polegar Diplodon berthae
16'. Bordas dorsal e ventral retas ou pouco abauladas, concha sem depressão interna oblíqua.

17. Borda posterior fortemente truncada e oblíqua, dente pseudocardinal posterior retangular e espesso com poucos dentículos radiais, perióstraco castanho .... Diplodon charruanus

17'. Borda posterior arredondada, dentes pseudocardinais baixos e lamelares

18. Extremidades anterior e posterior na metade da altura, dente pseudocardinal direito posterior lamelar longo, perióstraco de cor negra brilhante, na região posterior mais lamelar e sem brilho, concha pouco inflada .......... Diplodon pilsbryi

18'. Extremidade anterior e posterior regularmente arredondadas, borda ventral reta, dente pseudocardinal direito poste rior lamelar curto, perióstraco castanho-escuro, sem brilho, concha relativamente pequena e muito inflada

Diplodon koseritzi

19". Estrias concêntricas não evidentes, baixas e muito próximas entre si Corbicula largillierti

19'. Estrias concêntricas altas e espaçadas...Corbicula fluminea

20. Forma variável (discóide ou oval), região anterior pouco projetada e a posterior arredondada....... Pisidium globulus

20'. Forma variável (oval ou ovóide), região anterior bastante projetada e a posterior truncada e relativamente curta, geralmente formando um ângulo no encontro da margem dorsal com a posterior Pisidium sterkianum

21. Forma oval, umbos inflados com sulco mediano ..... Monocondylaea minuana

21'. Forma ovóide ou discóide, umbos baixos sem sulco mediano Monocondylaea corrientesensis

22. Forma elíptica-rombóide muito alongada, região posterior projetada e afilada, extremidade distal na metade da altura, pécilíndrico muito alongado, com extremidade intumescida Mycetopoda legumen

22'. Forma variável (oval, ovóide, trapezóide, elíptica-ovalado ou elíptica-reniforme), região posterior pouco projetada, com extremidade distal descendente, não afilada, pé de forma não cilíndrica em linguiforme...Anodontites ....... 23

23. Forma trapezóide, grande inflada, capa prismática reduzida A. trapesialis

23'. Forma variável não trapezóide, capa prismática geralmente larga. 24

24. Forma ovóide ou quase discóide, concha alta e inflada, cavidade umbonal profunda .......................... A. trapezeus

24'. Forma oval ou elíptica, concha baixa e pouco inflada, cavidade umbonal rasa ............................................ 25

25. Forma oval ................................................................. 26

25'. Forma elíptica ........................................................... 27

26. Charneira curva e espessa, umboslargos enão proeminentes, impressão do músculo adutor anterior bastante aprofundada e demarcada por várias linhas concêntricas e bem escuras A. iheringi 
26'. Charneira reta e pouco espessa, umbos levemente proeminentes, impressão do músculo adutor anterior pouco aprofundada e sem demarcações escuras ............ A. patagonicus

27. Forma elíptica-ovalado, perióstraco liso, com brilho na região anterior, nácar azulado-acinzentado, bordas dorsal e ventral reta ou levemente arqueadas. A. lucidus

27'. Forma elíptica-reniforme, perióstraco rugoso, sem brilho, nácar esverdeado com manchas de cor marrom, borda dorsal arqueada e a ventral geralmente deflexionada

A. tenebricosus

\section{Hyriidae Fleming, 1828 \\ Hyriinae Swainson, 1840 \\ Diplodon (Diplodon) aethiops (Lea, 1860)}

Fig. 2

Unio aethiops Lea, 1860: 91.

Unio dunkerianus: Clessin, 1888: 172 (non Lea, 1856).

Unio aethiops Lea var. piracicabana Ihering, 1893: 102 (partim).

Diplodon charruanus: Haas, 1930: 182 (partim); Haas, 1969; 515

(partim) (non Orbigny, 1835).

Diplodon parallelipipedon aethiops: Parodiz, 1968: 3 (partim); Mansur, 1970: 85.

Diagnose. Distingue-se pela forma elíptica-rombóide, eventualmente elíptica-lanceolada (altura 2,3 cm, comprimento 5,5 $\mathrm{cm})$, borda dorsal levemente curva, ventral reta, ponta posterior situada bem abaixo da metade da altura, no encontro da borda ventral; região posterior igual ou mais baixa que a anterior; concha relativamente sólida, mais inflada na região anterior, umbos baixos; escultura umbonal formada por raios curtos na região anterior, por muito curtos e convergentes na região central, e por longos posteriormente; perióstraco de cor variável (castanho-esverdeado ou castanho-escuro, quase negro) e brilhante; impressão dos músculos adutores anteriores muito grandes; dentes pseudocardinais lamelares e relativamente curtos.

Material examinado. BraSIL, Rio Grande do Sul: São Leopoldo (Parque dos Trabalhadores), 1v., 31.III.1984, M. Sander e alunos leg. (MZU 593); (banhado da Olaria Linck), 1 v., 31.III. 1984, M.E. de Paula Luchese leg. (MZU 749); (rio dos Sinos), 2 v., 25.V.1984, M. Sander e alunos leg. (MZU 712); açude do Centro de Ciências Exatas e Tecnológicas (UNISINOS), 8 ex.+9 v., X.1999, D. Pereira leg. (MCP 7642, 1 ex. com gloquídios); açude do Centro de Ciências da Saúde (UNISINOS), 14 ex. + 28, VII.2000, D. Pereira leg. (MCP 8290). U. dunkerianus: Rio de Janeiro: rio Macacu, s/d (holótipo NMNH 84155, coleção de Lea); D. aethiops: Urugual: (holótipo NMNH 85617); BrasiL: Rio Grande do Sul: Lagoa da Volta (SBMF 11185a, coleção de H. von Ihering, identificado por Haas 1930 como D. charruanus); rio Camaquã (NM NH 162388 em parte, coleção de H. von Ihering, que identificou como D. aethiopiformis).

Ocorrências ambientais. Em lagoas, canais e rios costeiros do Rio Grande do Sul, com areia escurecida por fina camada de matéria orgânica (MAnsur et al. 1991).
Comentário. Pela primeira vez foi observado o gloquídio desta espécie, que é do tipo parasito de peixe. O material foi encontrado em seco, aderido à valva direita de um exemplar possivelmente predado por uma ave na margem de um açude. O material fragilizado devido à exposição ao ambiente não permitiu preparações adequadas para publicação, mas encontra-se depositado na coleção do MCP.

O material identificado como "?Unio dunkerianus" Lea, 1856, por CLESSIN (1888), trata-se provavelmente de D. aethiops. Unio dunkerianus ocorre no Rio de Janeiro e apresenta concha lanceolada, internamente nacarada e externamente com briIho intenso, além de constituição muito frágil. Os exemplares de $D$. aethiops da bacia do rio dos Sinos apresentam o mesmo contorno elíptico-lanceolado, diferindo pela dentição cardinal menos alongada, pela redução da escultura umbonal e maior espessura das valvas.

Ao descrever D. aethiops Lea var. piracicabana, IHERING (1893: 1020) mencionou a nova variedade para o estado de São Paulo e para bacia do lago Guaíba, no estado do RS. Este material não foi localizado nas coleções científicas observadas. No entanto, examinou-se material identificado por Ihering como D. aethiops oriundo da Lagoa da Volta no estado do RS. A forma dos exemplares do SBMF 11185a da Lagoa da Volta coincide exatamente com os exemplares do rio dos Sinos e com a forma lanceolada do holótipo de Lea. Os demais exemplares (11185b, c) do mesmo lote são semel hantes à espécie D . berthae. Material muito similar a este, coletado por Ihering, contendo as duas espécies ( $D$. aethiops e $D$. berthae) oriundas do rio Camaquã, no RS, foi encontrado também no Museu de Washington, com etiquetas do próprio punho de $\mathrm{H}$. von Ihering, contendo a identificação de D. aethiopiformis. PARODIz (1968) e HAAS $(1930,1969)$ consideraram este último um nomen nudum. Todo este material foi identificado por $\operatorname{HAAS}(1930,1969)$ como D. charruanus. Segundo Mansur \& Silva (1999) esta última espécie apresenta gloquídio sem dentes (tipo não parasito) e D. berthae apresenta gloquídio com dentes (tipo parasito), o que comprova serem distintas apesar das semelhanças externas. Apesar das espécies D. aethiops e D. berthae apresentarem larvas do tipo parasito de peixe, consideramos como espécies válidas e distintas com base na forma (elíptica-rombóide ou elípticalanceolada em D. aethiops; elíptica-ovalada em D. berthae), na impressão do músculo adutor anterior (maior em D. aethiops) e na depressão interior (em D. berthae).

\section{Diplodon (Diplodon) berthae Ortmann, 1921 \\ Fig. 3}

Unio aethiops Lea var. piracicabana Ihering, 1893: 102 (partim). Diplodon berthae Ortmann, 1921: 528, est. 38, fig.1-4.

Diplodon charruanus: Haas, 1930: 182 (partim); Haas, 1969: 515; (partim) (non Orbigny, 1835).

Diplodon piceus: Parodiz, 1968: 9 (partim) (non Lea, 1860).

Diplodon rhombeus fontaineanus: Bonetto \& Mansur, 1970: 248 (partim) (non Wagner).

Revista Brasileira de Zoologia 23 (4): 1123-1147, dezembro 2006 
Diplodon charruanus: Mansur, 1970: 78 (partim).

Diplodon berthae: Mansur \& Silva, 1999: 475.

Diagnose: Distingue-se pela forma elíptica-ovalada (altura 2,6 cm, comprimento $5,7 \mathrm{~cm}$ ); concha relativamente sólida, umbos baixos; região anterior menor e mais estreita que a posterior, região posterior mais alta e bem mais inflada que a anterior; borda dorsal levemente curva, borda ventral variável entre descendente, reta ou deflexionada; ponta posterior formando um bico situado na metade da altura; escultura umbonal formada por raios curtos na região anterior, por raios muito curtos, convergentes na região central e por longos posteriormente; perióstraco de cor variável (de marrom-negro ao castanho) e brilhante; internamente observa-se uma elevação oblíqua que sai da cavidade subumbonal até a região mediana da concha, seguida de uma depressão ou concavidade como se as valvas tivessem sido pressionadas posteriormente por um dedo polegar; dentes pseudocardinais lamelares, com o posterior mais alto reforçado e crenulado, com dentículos radiais na parte dorsal.

Material examinado. BRASIL, Rio Grande do Sul: São Leopoldo (afluente do arroio da Manteiga), 5 ex., 23.IV.1975, V. Lopesleg. (MCN 31979); Cachoeira (rio Jacuí), s/d, J.D. Haseman leg. (lectótipo CM 61.5865, coleção de A.E. Ortmann); J.D. Haseman leg. (parátipo SBMF 4642a); Lagoa da Volta (SBMF 11185b,c, coleção de H. von Ihering, que identificou como D. aethiopiformis e por Haas 1930 como D. charruanus); rio Camaquã (NMNH 162388 em parte, coleção de H. von Ihering, que identificou como D. aethiopiformis). D. piceus: AmÉRICA DO SuL, Rio Uruguai, s/d, Wyman leg. (holótipo NMNH 85643).

Ocorrências ambientais. Em praia arenosa, no rio Jacuí e na foz do arroio Capivara, RS, em sedimento arenoso e lodoso (Pereira et al. 2000).

Comentário. Ortmann (1921) mencionou a possibilidade desta espécie ter alguma relação com o que IHERING (1893) chamou de D. aethiops para a drenagem do Guaíba. No entanto, segundo Ortmann (1921), este material de lhering difere do D. aethiops de LEA, autor da espécie, e corresponde às características de D. berthae. Esta constatação de OrTmann foi confirmada ao examinar o material (SBMF 11185 b, c) identificado por IHERING como D. aethiops. PARODIz (1968) considerou D. berthae como sinônimo de D. piceus (LeA 1860). No entanto, Mansur \& Silva (1999) preferiram considerar D. berthae como espécie válida para a bacia Atlântica do Sul do Brasil. As autoras descreveram pela primeira vez o gloquídio como do tipo parasito. ORTMANn (1921) havia observado as larvas desta espécie em fase ainda imatura.

\section{Diplodon (Diplodon) granosus multistriatus (Lea, 1831)} Fig. 4

Unio multistriatus Lea, 1831: 91.

Diplodon granosus multistriatus: Haas, 1931a: 32.

Diplodon elliptcus: Mansur, 1970: 73 (non Wagner in Spix, 1827).

Diagnose. Distingue-se pelo contorno ovóide (altura $3,4 \mathrm{~cm}$, comprimento $4,0 \mathrm{~cm}$ ); região anterior mais baixa que a posterior, borda dorsal ascendente e a posterior truncada, a ven- tral levemente arqueada, ponta posterior logo abaixo da metade da altura; concha frágil, umbos baixos; escultura umbonal formada por raios curtos na região anterior, por raios mais alongados e pouco convergentes na parte central e por curtos posteriormente, podendo aparecer granulações nas extremidades distais dos raios ou formando pequenos "Vs" imbricados, na região posterior; perióstraco castanho-amarelado e sem brilho; dentes pseudocardinais lamelares e curtos, o posterior levemente mais reforçado com dentículos radiais na parte dorsal.

Material examinado. Holótipo NMNH 84114, coleção de Lea; BrASIL, Rio Grande do Sul: Município de Santo Antônio da Patrulha (atual Município de Caraá), balneário João Fernandes, 6 ex. +3v., 11.XI.1997, C.V. Ribeiro leg. (MCP 6225); 3 ex., 30.I.94, D. Pereira leg. (MCP 8547); Rolante (rio da Areia), 1 v., 30.X.1988, M. E. Dasenbrok leg. (MZU 620); 3 v., 30.X.1988, M.E. Dasenbrok leg. (MZU 811); São Leopoldo (Parque dos Trabalhadores), 2 v., 31.III.1984, M. Sander e alunos leg. (MZU 745); Paraná: Curitiba (rio Palmital), 1959, A. A. Bonetto leg. (NMNH 6687). O material tipo de Diplodon ellipticus não se encontra mais na coleção de Spix que foi depositada na ZS. Segundo FECHTER (1983) as figuras das espécies descritas por Spıx (1827), com uma breve diagnose, são do próprio autor que veio a falecer precocemente, antes da sua publicação. Sua obra foi continuada por Wagner que completou as descrições com base apenas nos desenhos originais de Spix, o que justificaria as diferenças encontradas entre as medidas oferecidas por Wagner eo material tipo original. Tanto IHERING (1890) como FECHTER (1983), se preocuparam com o problema, revisando o material tipo e oferecendo ilustrações. No entanto, em relação a D. ellipticus, FECHTER (1983) coloca ilustrações, com dúvidas deum exemplar quenão corresponde ao da espécierevisada. Consideramos as ilustrações das duas val vas (vista interna) apresentadas por IHeRING (1890), estampa 9, figuras 8 e 9, como síntipos.

Ocorrências ambientais. Vivem, total ou parcialmente enterrados, em margens arenosas e argilosas de rios de pequeno porte, da bacia hidrográfica do rio I guaçu (ZANARDINI 1965) e rios da bacia atlântica.

Comentário. A espécie foi descrita com base em exemplares do Rio de Janeiro. Havia um hiato geográfico de ocorrência desde este estado até o Rio Grande do Sul até ZANARDINI (1965) registrar a espécie para o rio Barigui, afluente do rio Iguaçu, nas proximidades da cidade de Curitiba, no estado do Paraná. Os exemplares examinados são idênticos aos do material figurado e identificado por ZANARDINI (1965). O gloquídio desta espécie é do tipo parasito de peixe segundo Rıccı et al. (1990).

\section{Diplodon (Diplodon) martensi (Ihering, 1893)} Fig. 5

Unio martensi Ihering, 1893: 100.

Diplodon rhuacoicus: Haas, 1930: 180 (partim) (non Orbigny, 1835).

Diplodon martensi: Parodiz, 1968: 7; 1973: 263; Mansur, 1970: 74; Mansur \& Silva, 1999: 477; Mansur, 1999: 188.

Diplodon charruanus: Bonetto \& Mansur, 1970: 244 (partim) (non Orbigny, 1835). 
Diagnose. Distingue-se pela forma elíptica-retangulóide (2,6 al tura x 5,2 comprimento); região anterior curta, levemente mais baixa que a posterior, apresentando um leve achatamento oblíquo anterior, borda dorsal regularmente arqueada, ventral reta ou levemente arqueada, região posterior regularmente curva com ponta posterior situada na metade da altura; concha pouco espessa, pouco inflada, com umbos baixos; escultura umbonal formada por raios curtos na região anterior, por raios mais alongados e pouco convergentes na parte central (um ou mais raios centrais convergentes formando "Vs") e por curtos posteriormente, podendo aparecer granulações nas extremidades distais dos raios ou formando pequenos "Vs" imbricados na região posterior; perióstraco castanho-escuro com brilho seroso, em quase toda a superfície; dentes pseudocardinais lamelares e curtos, o posterior levemente reforçado.

Material examinado. BrasiL, Rio Grande do Sul: Campo Bom, 3 ex., 24.III.1971, P.C. Braun leg. (MCN 3160); Montenegro (arroio Bom Jardim), 7 exs, 20.XII.1977, M.C.D. Mansur leg. (MCN 5455); São Paulo? (holótipo SBM F 3929).

Ocorrências ambientais. No açude do Parque Copesul, Triunfo, RS, ocorreu tanto em fundo compactado e correnteza forte, como em fundo brando e com correnteza fraca (M ANSUR et al. 1994).

Comentário. O gloquídio desta espécie é do tipo parasito. Foi descrito por MANSUR \& SILVA (1999) e seu ciclo parasitário por MANSUR (1999).

\section{Diplodon (Diplodon) pilsbryi Marshall, 1928}

$$
\text { Fig. } 6
$$

Diplodon pilsbryi Marshall, 1928: 2.

Diplodon rhuacoicus: Haas, 1930: 180; Parodiz, 1968: 9 (partim);

Mansur, 1970: 77 (non Orbigny, 1835).

Diagnose. Distingue-se pela forma regularmente elípticaovalada (altura 3,2 cm, comprimento $6,1 \mathrm{~cm}$ ); bordas dorsal e ventral regularmante arqueadas, ponta posterior situada na metade da altura; umbos baixos; escultura umbonal formada por raios curtos na região anterior, por raios mais al ongados na parte central e por curtos posteriormente, sem granulações evidentes e sem convergência central; perióstraco negro e brilhante, na região posterior o perióstraco é mais lamelar e sem briIho; dentes pseudocardinais lamelares muito alongados.

Material examinado. BrasiL, Rio Grande do Sul: São Leopoldo (banhado da Olaria Linck), 2 vs, 11.XI.1985, M. Sander e alunos leg. (MZU 807); URUGUAI, D epartamento de Cerro Largo: Cañada Grande, Felipponeleg. (holótipo NM NH 368237).

Ocorrências ambientais. Em fundo arenoso de uma represa, no curso superior do arroio Capivara, RS, afluente do rio Jacuí, RS (Pereira et al. 2000, 2001).

Comentário. Bonetto (1964) considerou D. pilsbry como uma espéciemuito afim a Diplodon (D.) delodontus (Lamarck, 1819), cujo gloquídio foi descrito como parasito de peixe (Bonetro 1961). Falta, no entanto, um estudo descritivo do gloquídio de D. pilsbry para certificar seu enquadramento no subgênero Diplodon.
O material examinado é idêntico ao registrado para a microbacia do arroio Capivara, por Pereira et al. $(2000,2001)$ e do rio Camaquã, Rio Grande do Sul, por MANSUR \& ANFLoR (1981).

\section{Diplodon (Rhipidodonta) hildae Ortmann, 1921}

Fig. 7

Diplodon hildae Ortmann, 1921: 514.

Diplodon charruanus: Haas, 1930: 180 (partim); Haas, 1969: 515 (partim); Bonetto \& Mansur, 1970: 244 (partim);

Diplodon piceus Mansur, 1970: 78 (partim) (non Orbigny, 1835).

Diagnose. Distingue-se pela forma oval (altura $2,7 \mathrm{~cm}$, comprimento 4,3 cm); região anterior muito curta, bordas dorsal e ventral regularmante arqueadas, borda posterior truncada com ponta posterior situada na metade da altura; umbos baixos, escultura umbonal formada por raios geralmente curtos, com pouca convergência central e sem granulações; perióstraco castanho e brilhante; dentes pseudocardinais muito curtos, o posterior levemente arqueado.

Material examinado. BrasiL, Rio Grande do Sul: Campo Bom (arroio), 1 ex., 7.VI.1971, P.C. Braun leg. (MCN 3293); São Leopoldo, IV.1983, M. Sander e alunos leg. (MZU 435); (rio dos Sinos), 09.IV.1983, M. Sander e alunos leg. (MZU 705,752); (banhado da olaria Linck), 31.III.1984 M.E. de Paula Luchese leg. (MZU 750, 751, 813); 03.IX.1983, M. Sander e alunos leg. (MZU 464, MZU 465, MZU 470, MZU 471, MZU 744); 11.XI.1985, M. Sander e alunos leg. (MZU 708, MZU 814); (Parque dos Trabalhadores), 31.III.1984, M. Sander e alunos leg. (MZU 745); Porto Alegre (foz do rio dos Sinos, BR 59), 1 ex., 22.IX.1987 (MCN 31068); Cachoeira (rio Jacuí), J. D. Haseman leg. (CM Parátipo 1861.5864).

Ocorrências ambientais. Em substrato variado de seixos, areia e lodo, em correnteza forte e sem correnteza, em canais secundários do rio Jacuí, RS e tributários (MANSUR et al. 1988); em substrato arenoso na foz do arroio Capivara, no rio Jacuí (Pereira et al. 2000).

Comentário. Trata-se do primeiro registro desta espécie para a bacia do rio dos Sinos.

\section{Diplodon (Rhipidodonta) koseritzi (Clessin, 1888)}

\section{Fig. 8}

Unio koseritzi Clessin, 1888: 172.

Diplodon koseritzi: Mansur \& Silva, 1999: 477.

Diplodon charruanus: Haas, 1930: 182; Mansur, 1970: 78 (non Orbigny, 1835).

Diplodon charruanus: Bonetto \& Mansur, 1970: 244 (partim) (non Orbigny, 1835).

Diplodon piceus Mansur, 1970: 78 (partim) (non Orbigny, 1835).

Diagnose. Distingue-se pela forma elíptica-ovalada (altura 2,3 cm, comprimento $4,4 \mathrm{~cm}$ ); bordas dorsal e ventral levemente arqueadas, ponta posterior situada na metade da altura, região anterior levemente mais baixa que a posterior; concha baixa e inflada; escultura umbonal formada por raios curtos em pequeno número e pouca convergência central, sem 

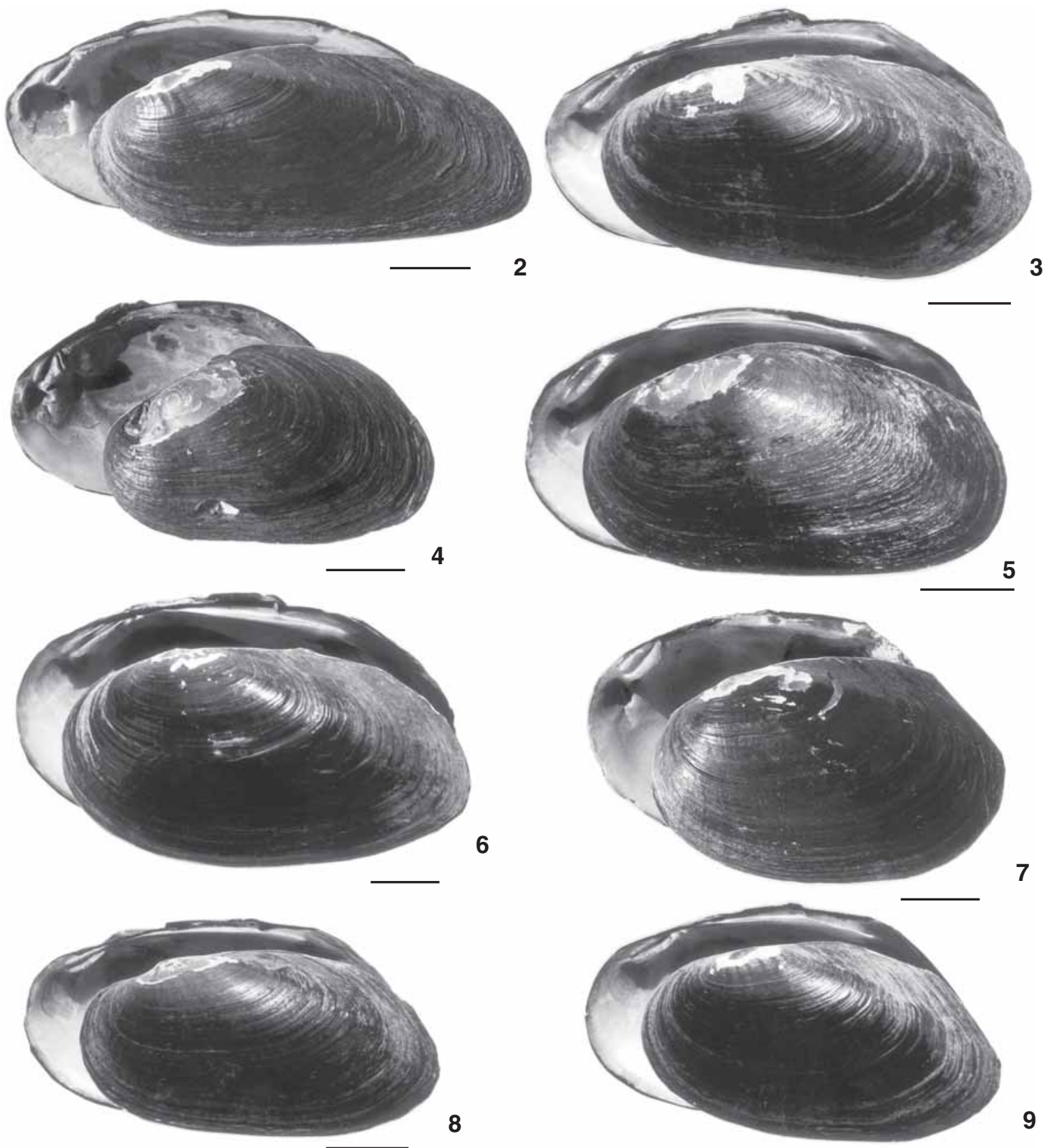

Figuras 2-9. Hyriidae, vista interna da valva direita e vista externa da valva esquerda: (2) Diplodon aethiops; (3) D. berthae; (4) D. granosus multistriatus; (5) D. martensi; (6) D. pilsbryi; 7. D. hildae; (8) D. koseritzi; (9) D. charruanus. Escala $1 \mathrm{~cm}$.

granulações; perióstraco castanho-escuro ou castanho-amare lado (nos exemplares jovens) e sem brilho; dentes pseudocardinais lamelares curtos, o posterior levemente mais espesso.

Material examinado. Brasil, Rio Grande do Sul: São Leopoldo (arroio da Manteiga), 1ex. 23.IV.1975, V.L. LopesPitoni leg. (MCN 4155).

Ocorrências ambientais. No lago Guaíba (Rio Grande do
Sul), habitam ambiente de águas calmas em sacos ou baias, associados à vegetação de juncos (M Ansur et al. 1999, 2003b).

Comentário. Os exemplares examinados correspondem as ilustrações oferecidas por HAAS (1930: 186, fig.5), relativas ao material tipo de Unio koseritzi descrito por CLESSIN (1888). O gloquídio desta espécie, do tipo não parasito, foi descrito por Mansur \& Silva (1999). Na bacia hidrográfica do lago Guaíba, a

Revista Brasileira de Zoologia 23 (4): 1123-1147, dezembro 2006 
área de ocorrência desta espécie tem sofrido pressão antrópica, principalmente através da poluição hídrica e destruição de habitats, bem como pela introdução de espécies exóticas e competidoras de moluscos, em especial o Mytilidae Limnoperna fortunei (Dunker, 1857). Tais fatores justificaram a inclusão de D. koseritzi na categoria "em perigo" da lista das espécies da fauna silvestre ameaçadas de extinção no Estado do Rio Grande do Sul (Mansur et al. 2003b).

\section{Diplodon (Rhipidodonta) charruanus (Orbigny, 1835) Fig. 9}

Unio charruana Orbigny, 1835: 35.

Diplodon charruanus: Haas, 1930: 182 (partim); Haas, 1969: 515 (partim); Bonetto \& Mansur, 1970: 244 (partim); Mansur, 1970: 78; Mansur \& Silva, 1999: 479.

Diagnose, distingue-se pela forma elíptica-ovalada (altura $2,2 \mathrm{~cm}$, comprimento $4,1 \mathrm{~cm}$ ), bordas dorsal e ventral regularmente arqueadas, borda posterior truncada com ponta posterior situada abaixo da metade da altura; umbos baixos, escultura umbonal formada por raios geralmente curtos, com pouca convergência central e sem granulações; perióstraco castanho ebrilhante; dente pseudocardinal posterior retangular, alto e espesso, crenulado, com poucos dentículos radiais.

Material examinado. BrASIL, Rio Grande do Sul: Taquara, Rio Paranhana, 1 v, 9.XI.1999, M. Bischoff \& D. Pereira leg. (MCP 7650); São Leopoldo (banhado da Olaria Linck), 9 vs, 03.IX.1983, M. Sander e alunos leg. (MZU 461, MZU 465, MZU 744); 6 vs, 11.XI.1985, M. Sander ealunos leg. (MZU 708); 2 vs, 11.XI.1985, M. Sander leg. (MZU 817, 818); 1938, R. Oberndorfer leg. (ZS 1103, Coleção de Modell, M 3326); (rio dos Sinos), 1 ex., 1996, alunos da escola 8 de Setembro em Estância Velha leg. (MCP 8294); Canoas (rio dos Sinos), fazenda Muradás, 3 ex., 22.XII.1997, Felipe Quadros leg. (coleção particular FCQ s/n); 1 ex. (MCP 8550). Urugual, 1ex. (holótipo BMNH 1854.9.4.15); lex. (parátipo SBMF 3916); 1 ex. (parátipo SBMF 4303).

Ocorrências ambientais. Registrada em água corrente com fundo de rocha, cascal ho e areia grosseira no arroio Colla, afluente do rio Rosário no Departamento de Colônia, Uruguai (MANSUR \& ANFLOR 1981).

Comentário. O gloquídio desta espécie, do tipo não parasito, foi descrito por MANSUR \& Silva (1999), com base em material coletado no Banhado do Taím (bacia da Lagoa Mirim).

\section{Diplodon (Rhipidodonta) deceptus Simpson, 1914 sensu Ortmann, 1921}

Fig. 10a, 10b

Diplodon fontainianus deceptus Simpson, 1914: 1450.

Diplodon deceptus Simpson, 1914 sensu Ortmann, 1921: 539.

Diplodon delodontus expansus: Haas, 1930: 192 (partim); Haas, 1969: 524-25 (partim) (non Küster, 1856).

Diplodon rotundus gratus: Parodiz, 1968: 4 (partim); Mansur, 1970: 67 (partim) (non Lea, 1860).
Diplodon delodontus wymanii: Bonetto \& Mansur, 1970: 249 (partim) (non Lea, 1860).

Diagnose. distingue-se pela concha robusta (altura $5,5 \mathrm{~cm}$, comprimento $6,9 \mathrm{~cm}$ ) e pela forma predominantemente discóide (Fig. 10b), às vezes ovóide (Fig.10a); região anterior muito curta, a posterior muito alta e arredondada, podendo ser truncada posteriormente (característica que originou o nome D. deceptus); borda dorsal muito arqueada e a ventral com maior abaulamento após o meio; umbos baixos, porém inflados; escultura umbonal formada por raios geralmente curtos, com pouca convergência central, podendo haver grãos distais, brilhantes formando fileiras radiais na região central da concha; perióstraco castanho e brilhante; charneira larga e reforçada com dentes pseudocardinais muito robustos, o posterior muito maior, apresentando lascas radiais.

Material examinado. D. deceptus: BraSIL, Rio Grande do Sul: São Leopoldo, 09.IV.1983 (MZU 428); (banhado da Olaria Linck), 1 V., 03.IX.1983, M. Sander e alunos leg. (MZU 462); 1v., 03.IX. 1983, M. Sander e alunos leg. (MZU 463); 1 v., 03.IX.1983, M. Sander e alunos leg. (MZU 469); 4v., 11.XI.1985, M. Sander e alunos leg. (MZU 709); 3 v., 03.IX.1983, M. Sander e alunos de Zool. leg. (MZU 754); 1 V., 11.XI.1985, M. Sander e alunos leg. (MZU 808); 1 V., 09.IV.1983, M. Sander leg. (MZU 815); 1 v., 09. IV.1983, M. Sander leg. (MZU 816); (rio dos Sinos), 1 v., 09.IV. 1983, M. Sander \& A.S. Junior leg. (MZU 711); 1 v., 09.IV.1983, M. Sander \& A.S. Junior leg. (MZU 809); 2v., 09.IV.1983, M. Sander \& A.S. Junior leg. (MZU 810); 3 ex., 1996, alunos da escola 8 de setembro em Estância Velha leg. (MCP 8291); (rio dos Sinos, Est. III), 1 ex., 27.IV.1979, CESB-DMAE leg. (MCN 7018); (olaria do arroio da Manteiga), 1 ex., 12.XI.1975, V.L. Lopes-Pitoni \& S.V. leg. (MCN 4668); 1 ex., 12.XI.1975, V.L. Lopes-Pitoni \& I.L. Veitenheimer leg. (MCN 4670); Pesqueiro (rio dos Sinos), 1 v., 5.IV.1975, K. Saalfeld leg. (MCN 4117); Canoas (rio dos Sinos), fazenda Muradás, 1 ex., 22.XII.1997, Felipe Quadros leg. (MCP 8549); 2 ex. (coleção particular FCQ s/n); Nova Santa Rita (rio dos Sinos) sob a ponte Tabaí-Canoas, 1 v., 16.XII.2003, D. Pereira \& M.C.D. Mansur leg. (MCP 8503); São Jerônimo, arroio do Conde, estação 13, 25.III.1982 (MCN 6629, Iamninário 110B 001 a 007, gloquídios); Porto Alegre, Ilha Grande dos Marinheiros, (MCN 3139, lamninário 137A 001 a 012, gloquídios); D . bischoffi: rio Santa Maria, H. von Ihering leg. (BMNH 1891.4.13.22.3, NMNH 122293); D. delodontus: (MHNG holótipo 1086/68); D. delodontus expansus: Mundo Novo (rio Santa Maria), 7 ex., $\mathrm{H}$. von Ihering leg. (SBMF 11124); São Leopoldo, 4 ex., H. von Ihering leg. (SBMF 11126); D. paranaensis funebralis: São Leopoldo, 1938, R. Oberndorfer leg. (ZS 1126, Coleção de Modell - M 3324); D. expansus: São Paulo: São Paulo (rio Tietê), (Z.S. s/n, coleção de Modell, M818).

Ocorrências ambientais. Em substrato variado de seixos, areia e lodo, em correnteza forte no rio Jacuí, RS, canais secundários e tributários (MANSUR et al. 1988); em substrato similar na foz do arroio Capivara e margens adjacentes do rio Jacuí (Pereira et al. 2000).

Comentário. Pela primeira vez foi observado o gloquídio

Revista Brasileira de Zoologia 23 (4): 1123-1147, dezembro 2006 
desta espécie (não parasito de peixe) em material depositado no $\mathrm{MCN}$, procedente do baixo rio Jacuí e no seu delta.

Material desta espécie proveniente da bacia do rio dos Sinos foi encontrado em coleções científicas com nomes distintos: D. bischoffi, coletado e identificado por Ihering, considerado nomen nudum por PARODIZ (1968); D. delodontus expansus, coletados por Ihering e identificado por HAAS (1930) e D. paranensis funebralis, identificado por Modell (ZS).

Apenas os exemplares da Fazenda Muradás (Fig 10b) apresentaram a forma típica arredondada como se observou em espécimes procedentes do lago Guaíba e do rio Jacuí (MANSUR et al. 1988, Pereira et al. 2000). Grande parte dos exemplares apresentaram-se mais alogados e baixos, no entanto a dentição, o contorno e forma da concha nas faces interna e externa conferem com o material tipo examinado.

\section{Castalia martensi (Ihering, 1891)}

Fig. 11

Castalina martensi Ihering, 1891: 477.

Castalina martensi: Haas, 1931a: 41; Haas, 1969: 532; Mansur \& Campos-Velho, 2000: 7.

Castalia ambigua: Clessin, 1888: 171 (non Lamarck, 1819).

Castalia undosa martensi: Bonetto \& Mansur, 1970: 251; Mansur, 1970: 249 (non Ihering, 1891).

Diagnose. Distingue-se pela concha de forma triangulareqüilateral (altura 5,5 cm, comprimento 5,1 cm); região anterior muito baixa; a posterior alta, com forte carena demarcada por um sulco posterior que parte dos umbos até a extremidade posterior e que, no encontro da borda ventral, se destaca em forma de bico; umbos baixos e salientes; escultura umbonal formada por raios geralmente longos que podem alcançar um terço da altura da concha; perióstraco castanho e sem brilho; charneira larga e reforçada com dentes pseudocardinais muito robustos, o posterior é muito maior, apresentando lascas radiais; dentes lamelares posteriores estriados obliquamente e ou apresentando superfície granulosa.

Material examinado. BRASIL, Rio Grande do Sul: rio Camaquã, 2 ex., 1890, Ihering leg. (síntipo BMNH s/n); 1 ex., 1890, Ihering leg., (holótipo SBMF 3785); São Leopoldo (banhado da Olaria Linck), 1 ex., 11.XI.1985, M. Sander leg. (MZU 821). C. ambigua: (holótipo MHNG 151, coleção Lamarck).

Ocorrências ambientais. Nas margens do lago Guaíba, em substrato de areia fina e na presença de junco (M ANSUR 1972); em canais secundários do rio Jacuí (Rio Grande do Sul) de correnteza fraca ou ausente e em poças d'água com substrato are noso (Mansur et al. 1988); no açude do Parque COPESUL de Proteção Ambiental (MAnsur et al. 1994) e nas margens arenosas com camada de matéria orgânica na foz do arroio Capivara no rio Jacuí (Pereira et al. 2000).

Comentário. CLESSIN (1888) citou C. ambigua para a bacia dos Sinos com base em dois exemplares muito jovens. MANSUR (1970) colocou esta citação como sinônimo de C. martensi. Nos exemplares jovens (altura $1,9 \mathrm{~cm}$, comprimento $2,0 \mathrm{~cm}$ ), de $\mathrm{C}$. martensi, os raios paral el os da escultura umbonal se alongam até ou além da metade da concha como em exemplares bem desenvolvidos (altura $3,6 \mathrm{~cm}$, comprimento $4,0 \mathrm{~cm}$ ) de $C$. ambigua, o que pode ter confundido o autor. Além disso, as bacias brasileiras com ocorrência conhecida de $C$. ambigua são as dos rios Uruguai, Amazonas e Paraná, nunca tinha sido registrada para as bacias do atlântico sudeste. O gloquídio parasito de $\mathrm{C}$. martensi foi figurado e descrito por Mansur \& CAmpos -Velho (1990, 2000).

\section{Mycetopodidae Gray, 1840 Monocondylaeinae Modell, 1942 Monocondylaea minuana Orbigny, 1835}

Fig. 12

Monocondylaea minuana Orbigny, 1835: 37.

Monocondylaea paraguayana: Haas, 1931a: 44; Haas, 1969: 554; Mansur, 1970: 51 (non Orbigny, 1835).

Monocondylaea minuana: Bonetto \& Mansur, 1970: 252; Mansur, 1974: 3-25.

Diagnose. Distingue-se pela forma oval (altura $3,3 \mathrm{~cm}$, comprimento $5,2 \mathrm{~cm}$ ), região anterior relativamente alta e projetada; umbos inflados, formando um bico projetado, levemente curvado para frente e acima da linha da charneira; nos exemplares jovens com umbos não erodidos aparece um sulco mediano; perióstraco lamelar castanho-amarelado ou castanhoavermelhado, sem brilho.

Material examinado. Monocondylaea minuana: BrASIL, Rio Grande do Sul: São Leopoldo (rio dos Sinos), 2 vs, 25.V.1984., M. Sander e alunos leg. (MZU 585), (banhado da Olaria Linck), 1 v., 11.XI.1985, M. Sander e alunos leg. (MZU 702); 1 v., 03.IX.1983, M. Sander e alunos leg. (MZU 706); 4 vs 31.III.1984, M.E. de Paula Luchese leg. (MZU 710); (Parque dos Trabalhadores), 5 vs, 31.III.1984, M. Sander e alunos leg. (MZU 594b). URUGUAI, Banda Oriental (rio del Rosário), (holótipo BMNH 1854.9.4.27, coleção do Orbigny); Monocondylaea paraguayana: ArgentinA, Corrientes (rio Paraná), (holótipo BMNH 1854.9.4.13, coleção do Orbigny).

Ocorrências ambientais. Em substrato de areia e seixos, em correnteza fraca no rio Jacuí, canais secundários e tributários (MANSUR et al. 1988); em substrato arenoso de lagoas e canais, na Estação Ecológica do Taím (M Ansur et al. 1991); junto ao dique do açude do Parque COPESUL de Proteção Ambiental (MANsur et al. 1994); em substrato arenoso com espessa camada de matéria orgânica na foz do arroio Capivara (Pereira et al. 2000).

Comentário. MANSUR (1974) avaliou a variabilidade da concha de M . minuana em toda a área de ocorrência da espécie. O material examinado se enquadra nas formas da bacia do lago Guaíba.

\section{Monocondylaea corrientesensis Orbigny, 1835}

Fig. 13

Monocondylaea corrientesensis Orbigny, 1835: 38.

Monocondylaea corrientesensis: Bonetto \& Mansur, 1970: 253.

Diagnose. Distingue-se pela forma ovóide ou discóide

Revista Brasileira de Zoologia 23 (4): 1123-1147, dezembro 2006 
(altura 4,8 cm, comprimento 5,0 cm); região anterior relativamente baixa e pouco projetada; concha pouco inflada; umbos relativamente baixos e pequenos com bico pequeno e pouco projetado, sem sulco mediano; perióstraco castanho-amarelado, pouco lamelar na região anterior, castanho-esverdeado e sem brilho na parte posterior.

Material examinado. BrASIL, Rio Grande do Sul: São Leopoldo (Parque dos Trabalhadores), 1 v., 31.III.1984, M. Sander e alunos leg. (MZU 594a); Argentina, Provincia deCorrientes: rio Batel (lectótipo BMNH 1854.9.4.28, coleção do Orbigny).

Ocorrências ambientais. Na Argentina em corpos lóticos de correnteza moderada ou corpos lênticos com vegetação aquática e águas claras (CAstelLanos \& LANDONı 1990).

Comentário. Esse é o segundo registro de coleta desta espécie para a bacia do lago Guaíba. A primeira citação foi feita por ORTMAnN (1921), com base em material coletado no município Cachoeira do Sul, no rio Jacuí.

\section{Anodontitinae Modell, 1942 Anodontites patagonicus (Lamarck, 1819)}

Fig. 14

Anodonta patagonica Lamarck, 1819: 88.

Anodontites patagonicus: Haas, 1931b: 95; Haas, 1969: 566;

Mansur, 1970: 39 (partim) (non Lamarck, 1819).

Anodontites patagonicus patagonicus: Bonetto \& Mansur, 1970:

254 (partim) (non Lamarck, 1819).

Diagnose. Distingue-se pela forma oval (altura 3,9 cm, comprimento 6,4 cm); região anterior relativamente alta, arredondada e projetada com a extremidade anterior situada na metade da altura da concha; região posterior alta levemente truncada, extremidade posterior arredondada situada logo abaixo da metade da altura; borda ventral reta ou levementearqueada; umbos pouco inflados, sem bico projetado; perióstraco de cor variável (castanho-avermel hado ao verde-amarelado), liso e com pouco brilho; nácar salmão-amarelado, salmão-esverdeado ou com bandas concêntricas alternadas entre o amarelo e o verde; capa prismática larga na metade anterior do comprimento da concha.

Material examinado. BRASIL, Rio Grande do Sul: Taquara do Mundo Novo, 5 ex., Ihering leg. (SBMF 12040a); Taquara (rio Paranhana), 1 ex., 12.XI.1999, M. Bischoff \& D. Pereira leg. (MCP 7649); Município de Caará (antigo Santo Antônio da Patrulha), balneário João Fernandes, rio dos Sinos, 1 ex., V.1999, C. Gimarães leg. (MCP 8288); Parobé (distrito do Poço Fundo, rio dos Sinos), 1 ex., 9.II.1999., I. V. Luz; M. Bischoff \& D. Pereira leg. (MCP 8293); São Leopoldo (Banhado da Olaria Linck), 5 vs, 03.IX.1983, M. Sander e alunos leg. (MZU 468, MZU 473); 8 v., 31.III.1984, M.E. de Paula Luchese leg. (MZU 694); AmÉrICA Do Sul, rios da bacia do rio da Prata e da Patagônia, Holótipo (MHN Genebra 1086/93).

Ocorrências ambientais. Em substrato lodoso de um canal de irrigação de arroz na microbacia do arroio Capivara, RS (Pereira et al. 2000).
Comentário. Material similar ao identificado por PeREIRA et al. (2000) como Anodontites sp. procedente do arroio Capivara, afluente do rio Jacuí, Triunfo, RS.

\section{Anodontites trapezeus (Spix, 1827)}

Fig. 15

Anodon trapezeus Spix, 1827; in Spix \& Wagner, 1827: 28.

Anodontites trapezeus: Haas, 1931b: 97; Haas, 1969: 568; Mansur, 1970: 42.

Anodontites mortonianus: Haas, 1931b: 94 (partim); Haas, 1969: 565.

Diagnose. Distingui-se pela forma ovóide ou quase discóide (altura 4,9 cm, comprimento 5,5 cm); região anterior arredondada, relativamente curta, pouco projetada, com a extremidade anterior situada acima da metade da altura da concha; região posterior muito alta e truncada, extremidade posterior arredondada situada na metade da altura; margem ventral muito abaulada com a mais inflada após a metade do comprimento da concha; umbos pouco inflados, com bico evidente; perióstraco de cor variável (castanho-avermelhado ou verde-escuro), liso e brilhoso; nácar devariável (alaranjado ou esverdeado) iridescente na região posterior; capa prismática larga na metade anterior.

Material examinado. BrasIL, Rio Grande do Sul: Taquara do Mundo Novo, lex., Ihering leg. (SBMF 12087); Taquara (rio Paranhana), 1 ex., 09.II.1999, I. V. Luz; M. Bischoff \& D. Pereira leg. (MCP 8292); Taquara, (rio Paranhana)L. T. P. Ely leg. (MCN 2614); São Leopoldo (rio dos Sinos), 4 v., 25.V.1984., M. Sander e alunos leg. (MZU 586); 2 v., 09.IV.1983, M. Sander \& A. Silva Junior leg. (MZU 698); (banhado da Olaria Linck), 3., 03.IX.1983, M. Sander e alunos leg. (MZU 730); 28 v., 31.III.1984, M.E. de Paula Luchese leg. (MZU 704); 2 v., 31.III.1984, M.E. de Paula Luchese leg. (MZU 696); (olaria do arroio da Manteiga), 6 ex., 12.XI.1075, V. Lopes \& I.L. Veitenheimer leg. (MCN 4669); (Parque dos Trabalhadores), 11 v., 31.III.1984, M. Sander e alunos leg. (MZU 590, 695, 703); Sapucaia do Sul (Parque Zoológico), 1 ex., 20.X.1975, Liliane leg. (MCN 4488); rio Solimões (holótipo ZS s/n, coleção do Spix).

Ocorrências ambientais. Em substrato arenoso, no canal do açude do Parque COPESUL, RS (MANSUR et al. 1994); substrato de areia e seixos, em corenteza fraca no rio Jacuí, RS, canais secundários e tributários (M ANsUR et al. 1988); substrato de areia com espessa camada de matéria orgânica na foz do arroio Capivara, RS (Pereira et al. 2000); substrato arenoso (valvas vazias junto com A. lucidus e A. iheringi), no rio Paranhana, Taquara, RS (dados de coleção, MCP).

\section{Anodontites Iucidus (Orbigny, 1835)}

Fig. 16

Anodonta lucida Orbigny, 1835: 40.

Anodontites lucidus: Haas, 1931b: 90; Haas, 1969: 558 (Orbigny, 1835).

Anodontites clessini: Ortmann, 1921: 594 (non Fischer, 1890).

Revista Brasileira de Zoologia 23 (4): 1123-1147, dezembro 2006 

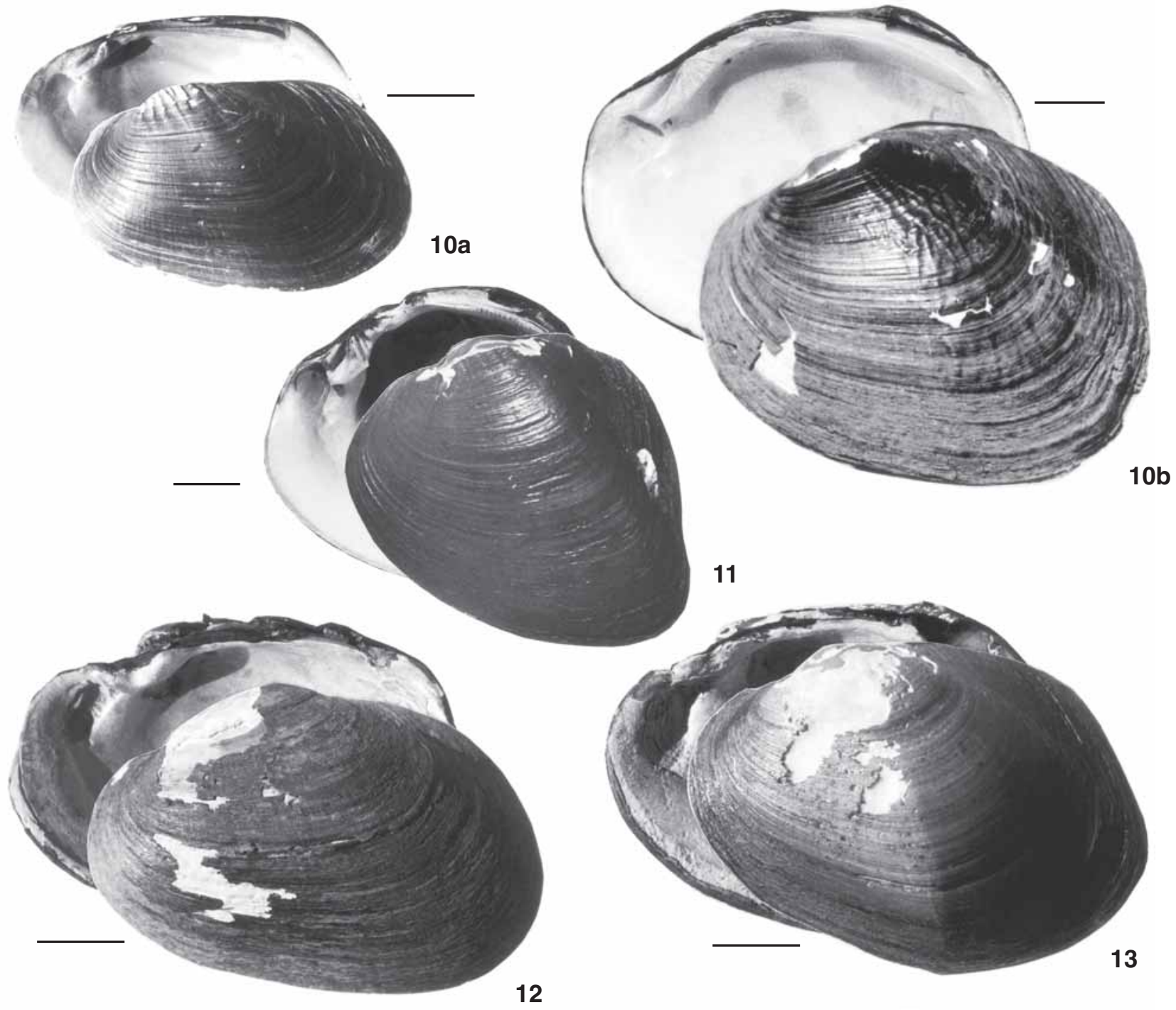

12
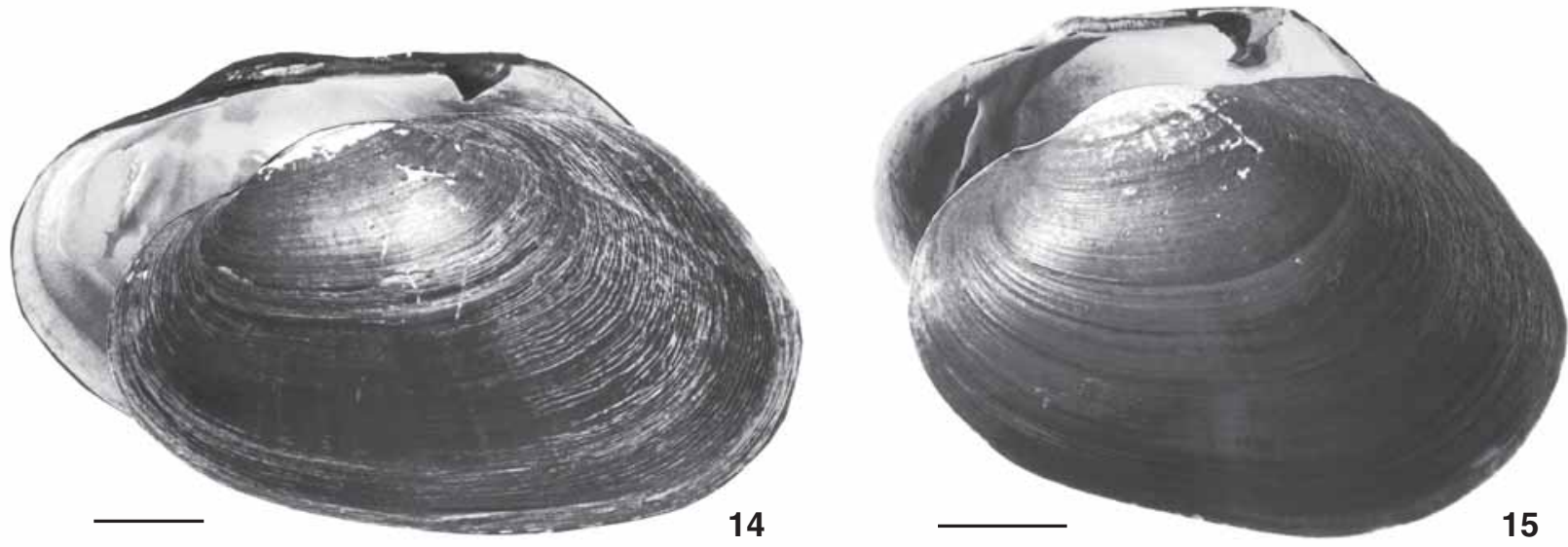

Figuras 10-15. Hyriidae, vista interna da valva direita e vista externa da valva esquerda: (10) D. deceptus: (a) jovem, (b) adulto; (11) Castalia martensi; (12) Monocondylaea minuana; (13) Monocondylaea corrientesensis; (14) Anodontites patagonicus; (15) A. trapezeus. Escala $1 \mathrm{~cm}$. 
Anodontites lucidus: Mansur, 1970: 48 (partim) (non Orbigny, 1835). Anodontites obtusus lucidus: Bonetto \& Mansur, 1970: 255 (non Orbigny, 1835).

Diagnose. Distingue-se pela forma regularmente elípticaovalada alongado (altura 3,0 cm, comprimento $5,9 \mathrm{~cm}$ ); região anterior relativamente muito projetada, regularmente arredonda, como a posterior que se apresenta al go mais alta e truncada; umbos pouco inflados, bico pouco projetado; perióstraco verdeescuro (raramente se distinguem os raios de cor mais escura, formando pequenos "vs" imbricados comuns em exemplares desta espécie registrados na bacia do rio Uruguai), liso e brilhante; nácar verde ou cinza muito escuro; capa primática evidente.

Material examinado. BraSIL, Rio Grande do Sul: Município de Igrejinha (rio Paranhana), 2 ex., 09.II.1999, I.V. Luz, D. Pereira \& M. Bischoff leg. (MCP 7646); Parobé, Distrito de Poço Fundo, 1 v, 10.II.1999, I.V.Luz \& D. Pereira leg. (MCP 7654); URugual, Colonia: rio Rosário, 4 ex. (lectótipo e paralectótipos BMNH 1854.12.4.834).

Ocorrências ambientais. Em substrato areno-siltoso no canal, de desagüe do açude do Parque COPESUL de Proteção Ambiental, bacia do rio Caí, RS (MANSUR et al. 1994); substrato arenoso (valvas vazias junto com $A$. trapezeus e $A$. iheringi), no rio Paranhana, Igrejinha, Rio Grande do Sul (dados de coleção, MCP).

Comentário. ORTMANn (1921) figurou exemplares coletados no rio Vacacaí, identificados erroneamente como A. clessini. No entanto, pelas ilustrações, deduz-se pertencer à espécie A . lucidus. Com base na obra de Ihering (1893), Ortmann (1921) mencionou o rio Santa Maria, como tributário do Ibicuí, local de ocorrência de A. clessini (=A. lucidus). Parece ter havido um segundo engano por parte de Ortmann. O rio Santa Maria mencionado por IHERING correspondia a um tributário do rio dos Sinos, atualmente denominado rio Paranhana, no município de Taquara (Ihering 1910, 1923), quando o autor visitou colônias alemãs (HENSEL 1867).

\section{Anodontites iheringi (Clessin, 1882)}

Fig. 17

Anodonta iheringi Clessin, 1882: 191.

Anodonta iheringi: Clessin, 1888: 171.

Anodontites mortonianus: Haas, 1931b: $94-95$ (partim); Haas, 1969: 565. (non Lea, 1834).

Anodontites iheringi: Morretes, 1949: 27.

Anodontites patagonicus patagonicus: Bonetto \& Mansur, 1970: 254 (partim).

Diagnose. Distingue-se pela forma oval (altura 3,6 cm, comprimento 5,9 cm); região anterior regularmente projetada, levemente afilada, e a região posterior truncada; bordas, dorsal e ventral, regularmente arqueadas; extremidade posterior abaixo da metade da altura; ligamento relativamente muito espesso assim como a concha junto à charneira, especialmente na região umbonal; umbos inflados, largos e o bico pouco evidente; Perióstraco verde-escuro (os raios de cor mais escuras às vezes visíveis), liso brilhante; nácar cinza com pouco brilho; im- pressão do músculo adutor anterior bastante demarcada e internamente com várias linhas concêntricas bem escuras; capa primática evidente, porém pouco espessa.

Material examinado. BRASIL, Rio Grande do Sul: Taquara do Mundo Novo (rio Santa Maria, atual rio Paranhana), 4 exs (a, b, e, f, o), H. Ihering leg. (provavelmente topótipos, SBMF 11995); 3 exs, Dr. P. Bohny leg. (NHMB 1642); açude, 8 exs (b, d, f, k, l, n, S, qu), H. Ihering leg. (SBMF 11992); I grejinha (29036' e 5050', rio Paranhana), 1 v., 09.II.1999, D. Pereira, M. Bischoff \& I. Luz leg. (topótipo, MCP 7644); Taquara (rio Paranhana), 1 ex., 09.II.1999, D. Pereira, M. Bischoff \& I. Luz (MCP 7643); 30 exs + 4 vs, T.P. Ely leg. (MCN 2614); Parobé (distrito do Poço Fundo, rio dos Sinos), 1 V., 9.II.1999., I. V. Luz; M. Bischoff \& D. Pereira leg. (MCP 7645); São Leopoldo (rio dos Sinos), 2 vs, 25.V.1984., M. Sander e alunos leg. (MZU 692); (rio dos Sinos, Est SIII, foz do canal da Av. João Correa), 1 ex., 16.II.1979, CESB-DMAE leg. (MCN 6458); (banhado da Olaria Linck), 2 vs, 03.IX.1983, M. Sander e alunos leg. (MZU 697); 1 ex., 11.XI.1985, M. Sander leg. (MZU 700); (Parque dos Trabalhadores), 4 vs, 31.III.1984, M. Sander e alunos leg. (MZU 695). Anodontites ferrarisi: URUguAl, Colônia, rio Rosário (lectótipo BMNH 1854.9.4.34, coleção Orbigny). O material tipo de Anodontites iheringi não foi localizado na coleção de Clessin depositada no SMNS. Considerou-se ilustrações de CLESSIN (1882), estampa 4, figura 5.

Ocorrências ambientais. Em fundo de areia compactada, no canal de desagüe do açude do Parque COPESUL de Proteção Ambiental, bacia do rio Caí, (M Ansur et al. 1994); margens arenopedregosas com deposição orgânica (valvas vazias), no rio Paranhana, Rio Grande do Sul (dados de coleção, MCP).

Comentário. Espécie originalmente descrita para o rio Santa Maria, atual rio Paranhana. Os exemplares examinados assemelham-se a Anodontites ferrarisi (ORBIGNY 1835) espécie revalidada por MANSUR \& OLAZARRI (1995); no entanto, são mais alongados e menos altos e nem todos os exemplares apresentam os raios finos de cor verde que podem estar anastomosados ou imbricados formando longas ornamentações com a forma da letra "v" sobre a área umbonal e central, que são característicos da espécie A. ferrarisi.

Restringe-se a localidade tipo de A. iheringi (CLESSIN 1882) para o rio Paranhana (2936'S e 5050'W), no município de Igrejinha. Tanto a localidade tipo como a área de ocorrência no lago Guaíba tem sofrido pressão antrópica, principalmente através da poluição hídrica e destruição de habitats, bem como a introdução de espécies exóticas de moluscos e competidoras. Tais fatores justificaram a inclusão da espécie na categoria vulnerável da lista das espécies da fauna silvestre ameaçadas de extinção no Estado do Rio Grande do Sul (MANSUR et al. 2003b).

\section{Anodontites tenebricosus (Lea, 1834)}

Fig. 18

Anodonta tenebricosa Lea, 1834,: 78; 1832-1874: 78.

Mycetopus plicatus Clessin, 1882: 191 (non Mycetopus plicatus Sowerby, 1868).

Revista Brasileira de Zoologia 23 (4): 1123-1147, dezembro 2006 
Mycetopus clessini Fischer, 1890: 8 (novo nome pro Mycetopus plicatus Clessin, 1882).

Glabaris nehringi Ihering, 1893: 60 (partim).

Glabaris clessini: Simpson, 1900: 930.

Anodontites clessini: Simpson, 1914: 1450.

Anodontites soleniformis: Haas, 1931b: 93; Haas, 1969: 564.

Anodontites (Anodontites) crispatus tenebricosus: Mansur, 1970: 44; Bonetto \& Mansur, 1970: 255.

Anodontites (A.) crispatus soleniformis: Mansur, 1970: 46.

Diagnose. Distingue-se pela forma elíptica-reniforme (altura $2,8 \mathrm{~cm}$, comprimento $7 \mathrm{~cm}$ ); borda dorsal arqueada e a ventral deflexionada; região anterior mais baixa e afilada, a posterior mais al ta levemente truncada junto à região dorsal e arredondada em direção a região ventral; concha pouco sólida, umbos baixos; perióstraco verde-escuro, fosco e geralmente desgastado; nácar muito escuro, de cor cinza-esverdeado, com manchas marrom e pouco iridescente; capa prismática larga.

Material examinado. BraSIL, Rio Grande do Sul: Santo Antônio da Patrulha (rio dos Sinos), 4 exs, 19.XI.1996, C.G. Silva leg. (MZU 819); 1 ex., 19.XI.1996, C.G. Silva leg. (MCP 7647); 2 ex. + 1 v., V.1999, C. Guimarães leg. (MCP 8289); Munic. Caraá (ex Munic. Santo Antônio da Patrulha) Balneário João Fernandes 1 ex., 30.I.1994, C.G. Silva leg. (MCP 7653); 4 ex +1 v., 14.XI.1997, C.V. Ribeiro leg. (MCP 6224); colônia deTaquara do Mundo Novo (rio Santa Maria, atual Paranhana), 2 exs + 1v., 1881, H. von Ihering leg. (SBMF 11966, na etiqueta constava A. soleniformis, Ihering det.).

Ocorrências ambientais. Segundo CASTELLANos \& LANDonI (1990) esta espécie é muito comum na bacia do rio Uruguai, em fundo arenoso e muito pedregoso, de águas bastante velozes e claras.

Comentário. CLESSIN (1882) descreveu Mycetopus plicatus para Taquara do Mundo Novo. Fischer (1890) constatou que o nome dado por Clessin era um homônimo de outra espécie descrita por SoWERBY (1868), oferecendo o novo nome Mycetopus clessini a M. plicatus. IherIng (1893), desconhecendo o trabalho de FISCHER (1890), propos a nova espécie Glabaris nehringi, com base na figura de CLESSIN (1882) e no exame de exemplares "idênticos", coletados no rio Santa Maria (atual rio Paranhana, da bacia do rio dos Sinos). O material que Ihering coletou no rio Piracicaba, São Paulo, colocando sob o mesmo nome G. nehringi, pertence provavel menteà espécie A. soleniformis. SIMPSON (1914) organizou pela primeira vez esta sinonímia, reunindo a espécie A. clessini ao grupo de A. tenebricosus.

HAAS (1931b) citou A. soleniformis para Taquara. O exame de exemplares de A. tenebricosus, procedentes das nascentes deste rio demostrou a presença de formas muito alongadas semeIhantes a A. soleniformis, o que levou o autor a uma identificação errônea. Formas muito semelhantes às encontradas no rio dos Sinos foram identificadas por ZANARDINI (1965) como A. tenebricosus para o rio Atuba, no município de Curitiba, Paraná. BonetTo \& EZCURRA (1965) revisaram a espécie e concluiram que seria impossivel separar A. tenebricosus de A. soleniformis. Assim, reuniram ambas como subespécies de Anodontites crispatus ssp. e delimitaram a área de ocorrência da primeira para o Paraná inferior, rio da Prata e rio Uruguai e a A. crispatus soleniformis para o alto Paraná e Paraguai. Bonetro (1967) colocou A. soleniformis na sinonímia de $A$. crispatus tenebricosus considerando esta como uma forma mais alta e menos alongada, que predominaria nas bacias dos rios da Prata e Uruguai. MAnsur (1970) considerou M. plicatus como sinônimo de A. crispatus tenebricosus e $G$. nehringi como sinônimo de A. crispatus soleniformes. Faltam ainda estudos mais detalhados sobre as variações populacionais e a biogeografia destes táxons a fim de definir melhor a separação ou não, em categorias específicas ou subespecíficas.

\section{Anodontites trapesialis (Lamarck, 1819)}

\section{Fig. 19}

Anodonta trapesialis Lamarck, 1819: 87.

Anodonta gigantea: Clessin, 1888: 171 .

Anodonta riograndensis Ihering, 1890: 158.

Anodontites exoticus susanae: Haas, 1931b: 101 (partim); Haas, 1969.

Anodontites trapesialis trapesialis: Haas, 1931b: 98 (partim).

Anodontites trapesialis forbesianus: Mansur, 1970: 35-38;

Veitenheimer, 1973b: 32-49.

Anodontites trapesialis susanae: Bonetto \& Mansur, 1970: 256.

Diagnose. Distingue-sepela forma trapezóide(altura $7,3 \mathrm{~cm}$, comprimento $12 \mathrm{~cm}$ ), valvas infladas, de espessura relativamente fina; região anterior mais baixa, com a extremidade anterior arredondada, porém levemente projetada acima da metade da altura; região posterior mais alta que a anterior e truncada obliquamente, com a aresta posterior abaixo da metade da altura; borda dorsal quase reta, a ventral arqueada e mais projetada ventralmente na metade posterior; umbos inflados e largos, com os bicos (extremidade distal dos umbos) pouco evidenciados; perióstraco varia do verde-claro ao verde-escuro, liso brilhante, podendo apresentar raios esverdeados; nácar prateado-esverdeado ou cinza-azulado, iridescente; capa primática evidente, porém estreita.

Material examinado. BraSIL, Rio Grande do Sul: Novo Hamburgo (margem direita do rio dos Sinos, no arroio Luiz Rau também denominado arroio Preto), 12 exs +4vs, C.J. Becker leg. (MCN 5507); São Leopoldo, 2 vs, 9.IV.1983 (MZU 429); (olaria do arroio da Manteiga), 8 exs, 12.XI.1975, V. Lopes, I. L. Veitenheimer, Beth $\&$ Karin leg. (MCN 4536); (riacho afluente do arroio da Manteiga), 4 exs, 23.V.1975, V. Lopes leg. (MCN 4172); (arroio da Manteiga), 2 exs, 23.IV.1975 V. Lopes leg. (MCN 4236); (banhado da olaria Linck), 2 v., 11.XI.1985, M. Sander e alunos leg. (MZU 588, 693); (Parque dos Trabalhadores), 1 v., 31.III.1984, M. Sander e alunos leg. (MZU 699); (Estação Ecológica Municipal em São Leopoldo, em meandro lateral em forma de ferradura do rio dos Sinos), 1 ex., 1999, Zildo leg. (MCP 7648); São Leopoldo (rio dos Sinos, 5 km oeste da sede do município), 2 exs, 1967 C.O. Berg leg. (CM 1968-4); Taquara do Mundo Novo, 1 ex., H. v. Ihering leg. (SBMF 12098); Sapucaia do Sul (lago do Parque Zoológico), 3 exs, 21.X.1989, M. T. Q. Melo \& R.P. Leal leg. (MCN 31999).

Revista Brasileira de Zoologia 23 (4): 1123-1147, dezembro 2006 


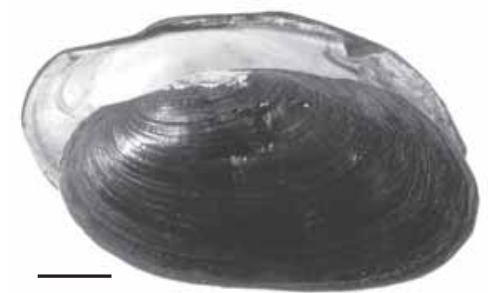

16

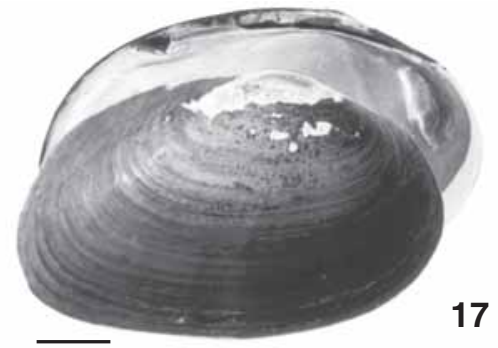

17
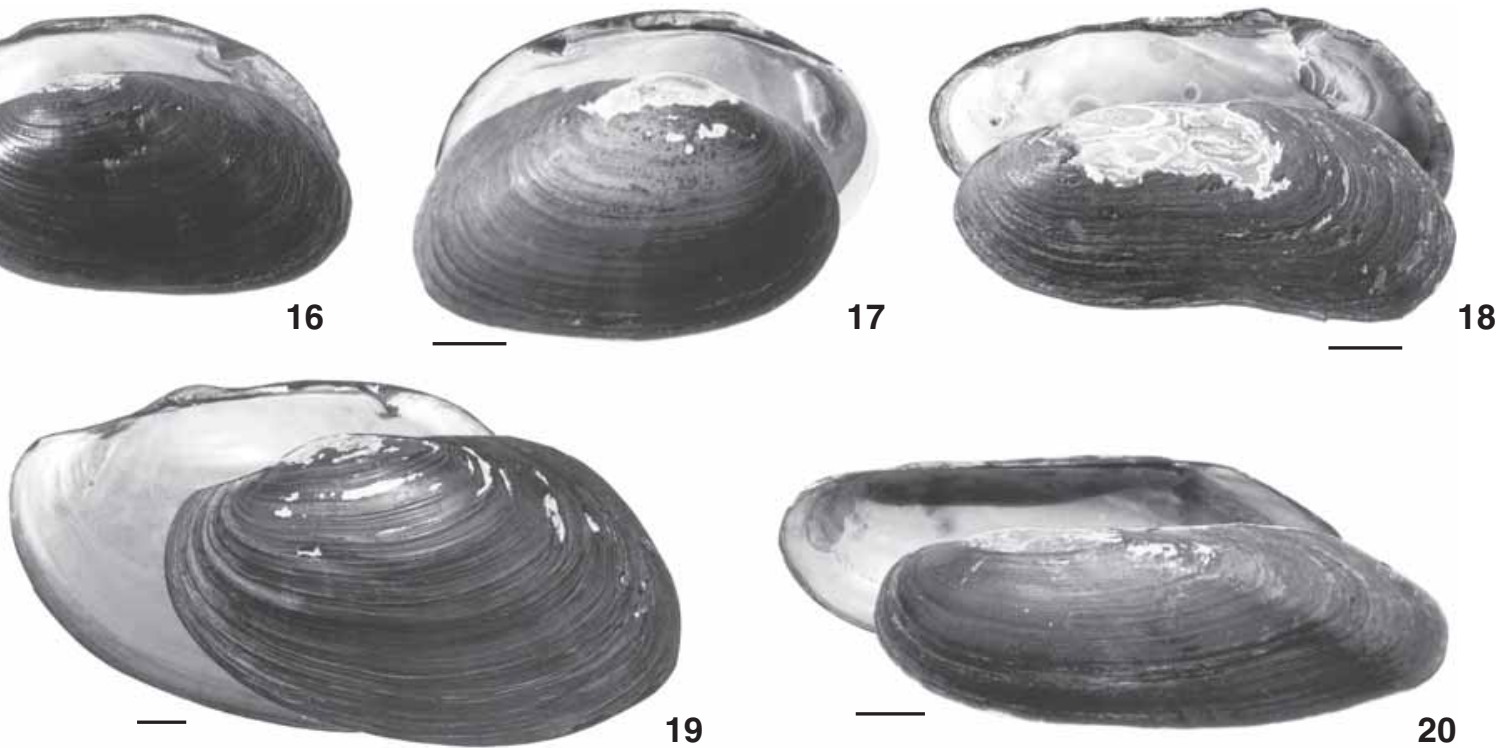

Figuras 16-20. Mycetopodidae: (16-17) vista interna da valva direita e vista externa da valva esquerda: (16) Anodontites lucidus; (17) vista interna da valva esquerda e vista externa da valva direita de A. iheringi; (18-20) vista interna da valva direita e vista externa da valva esquerda: (18) A. tenebricosus; (19) Anodontites trapesialis; (20) Mycetopoda legumen. Escala $1 \mathrm{~cm}$.

Anodonta trapesialis: BraSIL, (holótipo MHNG 1086/83, ex.11 e 12, coleção Lamarck); Anodonta riograndensis: Brasil, Rio Grande do Sul, rio Camaquã, 4v., s/d, H. v. Ihering leg. (BMNH $s / n$,); $A$. giganteus: BrASIL, rio Solimões ( 6 síntipos da coleção de SPIX, ZS s) n); Anodontites forbesianus: rio Uruguai, Wyman leg. (NMNH 86694, coleção de Lea).

Ocorrências ambientais. Ocorreram em substrato de areia e seixos, em correntezas fortes, fracas ou ausentes, no rio Jacuí e alguns de seus tributários (MANSUR et al. 1988); em areia coberta por espessa camada de matéria orgânica, nas lagoas da Estação Ecológica do Taím (MAnsur et al. 1991); em canal com água corrente forte e fundo arenoso compactado e em fundo arenoso mole com correnteza fraca, no Parque COPESUL (MAnsur et al. 1994); em fundo lodoso de açudes e canais de irrigação, na microbacia do arroio Capivara (PereIRA et al. 2000); no lago Guaíba, junto ao junco e na areia fofa sem limo (Veitenheimer 1973b).

Comentário. As valvas examinadas de A. trapesialis apresentam contorno variado, sendo que, dentre as formas ilustradas por Simone (1994), quatro delas puderam ser distinguidas: D, I, H eJ. Esta variação provavel mente levou os autores CLESSIN (1888) e HAAS (1931b) a citarem nomes diferentes para esta espécie, no rio dos Sinos.

\section{Mycetopodinae Adams \& Adams, 1856 Mycetopoda legumen (Martens, 1888)}

Fig. 20

Anodonta legumen Martens, 1888: 65.

Mycetopoda legumen: Ihering, 1910: 120; Ihering, 1923: 537; Haas,

1931b: 103; Haas, 1969: 576; Bonetto \& Mansur, 1970: 253;
Mansur, 1970: 48; Veitenheimer-Mendes \& Mansur, 1978a: 38; 1978b: 532; Mansur \& Veitenheimer-Mendes, 1979: 698.

Diagnose. Distingue-se pela forma elíptica-rombóide (altura $3 \mathrm{~cm}$, comprimento $8,5 \mathrm{~cm}$ ), com extremidade anterior curta, arredondada e mais estreita em relação a região posterior, que forma uma ponta mediana ou com tendência ventral, margem posterior truncada obliquamente, margem dorsal geralmente reta, continuando-se com a margem posterior e a anterior normalmente sem formar ângulo, margem ventral levemente arqueada; carena posterior baixa diminuindo gradualmente; umbos pouco proeminentes e desgastados, situados em torno de $1 / 4$ do comprimento da concha; valvas pouco entreabertas na região anterior; perióstraco varia do amarelo-esverdeado ao castanhoavermel hado, brilhante na região anterior e mediana; linhas de crescimento notórias, percebendo-se às vezes demarcações mais escuras; o pé apresenta intumescência distal, porém pode recoIher-se inteiramente para o interior da concha, o que não acontece com as demais espécies do gênero.

Material examinado: BrasiL, Rio Grande do Sul : Novo Hamburgo (poço do carvão, margem esquerda do rio dos Sinos), 23.VI, 28.III.1986, C. J. Becker leg. (MCN 30006); São Leopoldo (arroio da Manteiga), 12 ex., I. L. Veitenheimer, V. Lopes \& Sherer leg. (topótipos MCN 4537); São Leopoldo (Parque dos Trabalhadores), 2 V., 31.III.1984, M. Sander e alunos leg. (MZU 592); Canoas (fazenda Muradás, rio dos Sinos), 1 ex., 22.XII. 1997, Felipe Quadros leg. (coleção particular FCQ s/n).

Ocorrências ambientais. Em substrato de areia fina e compactada em águas abrigadas no arroio da Manteiga, afluente do rio dos Sinos, e no lago Guaíba, entre Ponta Grossa e

Revista Brasileira de Zoologia 23 (4): 1123-1147, dezembro 2006 
Ponta da Cuíca (Veitenheimer-Mendes \& Mansur 1978a); açude e canal de fundo lodoso do sistema de irrigação do arroio Capivara (Pereira et al. 2000).

Comentário. MANSUR \& VeITenheimer-M endes (1979) restringiram a localidade tipo da espécie para o arroio da Manteiga, afluente do rio dos Sinos, São Leopoldo. Tanto a localidade tipo como a área de ocorrência, no lago Guaíba, têm sofrido forte pressão antrópica, através da poluição hídrica, destruição de habitats, e principalmente devido à introdução de espécies exóticas de moluscos. Tais fatores justificaram a inclusão da espécie na categoria vulnerável da lista das espécies da fauna silvestre ameaçadas de extinção no Estado do Rio Grande do Sul (Mansur et al. 2003b).

\section{Leilinae Morretes, 1949 Leila blainvilliana (Lea, 1834) Fig.21}

Anodonta blainvilliana Lea, 1834: 78. Leila blainvilleana: Haas, 1931b: 102. Leila blainvilleana: Bonetto \& Mansur, 1970: 255.

Leila blainvilliana: Veitenheimer, 1973a: 67.

Diagnose. Distingue-se pela forma trapezóide e oblíquo (altura 6,6 cm, comprimento $10 \mathrm{~cm}$ ); umbos na posição anterior, muito inflados; charneira sinuosa, levemente alada na frente dos umbos formando um bico; cavidade subumbonal rasa, com várias impressões dos músculos dorsais dispostas em fileira oblíqua; linha palial retilínea ou côncava em relação à margem ventral, forma um sinus anterior ao músculo adutor posterior, arredondado ou anguloso e profundo; fresta intervalvar evidente na direção antero-posterior; perióstraco de cor variável (castanho-claro, castanho-escuro ou castanho-esverdeado); capa prismática muito estreita.

Ocorrências ambientais. Em substrato areno-lodoso, no Porto Belinho, próximo à foz do arroio Capivara no rio Jacuí (Pereira et al. 2000); em substrato arenoso, sem correnteza, em canais secundários do rio Jacuí e no arroio do Conde (M ANSUR et al. 1988); no lago Guaíba junto aos juncos e em areia fofa sem limo (Veitenheimer 1973a).

Comentário. Veitenheimer (1973a) revisou a espécie e restringiu a localidadetipo à praia do Guarujá, no lago Guaíba, no município de Porto Alegre, no estado do Rio Grande do Sul, Brasil. Registra-se L. blainvilliana pela primeira vez para a bacia do rio dos Sinos.

Material examinado. BrasIL, Rio Grande do Sul: Canoas (fazenda Muradás, na margem arenosa do rio dos Sinos), 1 ex., 22.XII.1997, Felipe Quadros leg. (MCP 8546).

\section{Corbiculidae Gray, 1847 Cyanocyclas limosa (Maton, 1811)}

Fig. 22

Tellina limosa Maton, 1811: 325.

Corbicula (Cyanocyclas) guahybensis Marshall, 1927: 4.
Corbicula (Cyanocyclas) iheringi Marshall, 1927: 6.

Neocorbicula limosa: Parodiz \& Hennings, 1965: 69; Garces et al., 1989: 507; Focht \& Veitenheimer-Mendes, 2001: 38.

Diagnose. Distingue-se das espécies do gênero e de Corbicula pela presença de um pequeno sinus palial de formato triangular junto ao músculo adutor posterior, sifões alongados, e concha praticamente lisa (sem ondulações comarginais, que são muito evidentes em Corbicula), e das demais espécies de Cyanocyclas pela concha mais baixa, menos inflada e umbos pouco projetados acima da linha da charneira.

Ocorrências ambientais. Em margens arenosas de lagoas e canais na Ecológica do Taím (MANSUR \& GARCES 1988); em profundidades inferiores a $2 \mathrm{~m}$, em leito arenoso, no lago Guaíba (Focht \& Veitenheimer-Mendes 2001).

Comentário. Distingue-se das espécies exóticas também por ser vivípara, com um período longo de incubação, liberando alguns indivíduos jovens de dimensões geralmente acima de $2 \mathrm{~mm}$.

Dentre o material coletado no Guaíba e Rio dos Sinos, que foi presenteado por $\mathrm{H}$. von Ihering ao USNM, MARSHALL (1927) descreveu duas espécies novas para o gênero Corbicula (Cyanocyclas). Com base em uma só valva oriunda de São Leopoldo, este autor homenageou o coletor doador decrevendo Corbicula iheringi cujas medidas correspondem a $22 \mathrm{~mm}$ de comprimento, 18,5 $\mathrm{mm}$ de altura e $12 \mathrm{~mm}$ de diâmetro (medida estimada, caso as duas valvas estivessem presentes). Trata-se do primeiro registro do gênero e da espécie para a referida bacia. Posteriormente, PARodiz \& Hennings (1965) colocaram a espécie C. iheringi na sinonímia de $\mathrm{C}$. limosa.

Até pouco tempo este gênero era mais conhecido como Neocorbicula Fischer, 1887, segundo revisão de PARODIZ \& HENNINGS (1965). Mais recentemente, PAROdIz (1996: 266) reconheceu a prioridade de Cyanocyclas, gênero endêmico da parte mais leste da América do Sul (Parodiz \& Hennings 1965).

A reprodução e distribuição sazonal de uma população de C. limosa da bacia hidrográfica do lago Guaíba, a qual está inserida a bacia do rio dos Sinos, foram descritas por Fochт \& Veitenheimer-Mendes (2001).

Material examinado. BrasıL, Rio Grande do Sul: São Leopoldo (rio dos Sinos, entrada do arroio Kruze), 5 exs, 5.X. 1973, I.L.Veitenheimer leg. (MCN 3692).

\section{Corbicula Iargillierti (Philippi, 1844)}

Fig. 23

Cyrena largillierti Philippi, 1844: 163.

Cyrena largillierti: Philippi, 1847: 75.

Corbicula largillierti: Prashad, 1929: 51.

Corbicula manilensis: Veitenheimer-Mendes, 1981: 65 (non Philippi, 1844).

Corbicula largillierti: Martins et al., 2004: 132.

Diagnose. Distingue-se das demais espécies do gênero por apresentar a concha (altura 1,6 e comprimento 2,61 mm) com as estrias concêntricas da superfície externa mais baixas e mui- 
to próximas entre si; forma da concha é mais al ongada no sentido antero-posterior que na altura, os umbos são mais baixos, perióstraco mais amarelado e o nácar roxo-acincentado. Integripaliada (sem sinus palial).

Material examinado. BRASIL, Rio Grande do Sul: Taquara (rio Paranhana), 2 exs, 9.II.1999, I. V. Luz, M. Bischoff \& D. Pererira leg. (MCP 8548); Taquara (rio Paranhana), 18 exs 09.II.1999, I.V. Luz, M. Bischoff \& D. Pereira leg. (MCP 7651); Parobé (distrito do Poço Fundo, rio dos Sinos), 2lexs + 3 vs 09.II.1999, I. V. Luz; M. Bischoff \& D. Pereira leg. (MCP 7652); São Leopoldo (banhado da Olaria Linck), 11.XI.1985, M. Sander leg. e alunos (MZU 755); Nova Santa Rita (ponte Tabaí-Canoas, rio dos Sinos), 6 ex +7 vs, 16.XII.2003, D.Pereira \& M.C.D. Mansur leg. (MCP 8500).

Ocorrências ambientais. Valvas vazias foram obtidas no rio Paranhana (Taquara) junto com A. lucidus e A. patagonicus; nas margens pedregosas do rio Parahana, Igrejinha, nas margens arenosas íngremes do rio dos Sinos, Parobé; nas margens arenosas delagoase canaisna Estação Ecológica do Taím (M ANSUR \& GARCES 1988); em canal deágua correnteem fundo compactado no Parque COPESUL de Proteção Ambiental (MANsur et al. 1994).

Comentário. Esta espécie é facilmente confundida com $\mathrm{C}$. fluminea, no entanto apresenta a concha mais frágil, menor altura e umbos mais baixos. CALLIL \& MANSUR (2002) observaram diferenças significativas quanto ao comprimento, altura, largura e peso da concha seca e com partes moles, entre esta espécie e C. fluminea, em populações do Pantanal do Mato Grosso. Tanto estas autoras como DARRIGRAN (1991) observaram queC. Iargillierti é pioneira e que após a chegada de $C$. fluminea a primeira desaparece aos poucos, provavelmente devido à competição interespecífica. MARTINS et al. (2004) compararam e diferenciaram três espécies do gênero (C. fluminea, $C$. largillierti e $C$. aff. fluminalis) no lago Guaíba, em Viamão, Rio Grande do Sul.

\section{Corbicula fluminea (Müller, 1774)}

Fig. 24

Telina fluminea Müller, 1774: 214.

Corbicula fluminea: Prashad, 1929: 51.

Corbicula fluminea: Martins et al., 2004: 131.

Diagnose. contorno triangular equilateral, concha relativamente robusta (altura 1,8 e comprimento $2 \mathrm{~mm}$ ); com umbos altos, inflados e afilados distalmente; estrias concêntricas da superfície externa, muito evidentes, altas e espaçadas; região posterior ligei ramente projetada, formando o "rostro" conforme ITUARTE (1994), com a aresta posterior situada bem abaixo da impressão do músculo adutor posterior; perióstraco marrom-amarelado ou marrom-esverdeado, geralmente brilhante; nácar branco ou levemente amarelado e sem brilho no centro, com a borda abaixo da linha palial, arroxeada ou marrom, com certo brilho; sem sinus palial.

Material examinado. BrasiL, Rio Grande do Sul: Nova Santa Rita (ponte Tabaí-Canoas, rio dos Sinos), 2ex. + 7 vs, 16.XII. 2003, D.Pereira \& M.C.D Mansur leg. (MCP 8501).

Ocorrências ambientais. Em sedimento arenoso nas mar- gens do rio dos Sinos

Comentário. Espécie de origem asiática introduzida na bacia do lago Guaíba posteriormente à chegada de Corbicula largillierti que foi coletada pela primeira vez na década de 1970 e reconhecida inicialmente como Corbicula manilensis (Philippi, 1841) por VeITENHEIMER-Mendes (1981). Em áreas de maior correnteza da água ou batimento de ondas provocadas pelo vento, a espécie costuma apresentar-se muito erodida na área umbonal, menor altura, coloração escura e sem brilho, em relação às populações de águas mais calmas. Este fenômeno, estudado e ilustrado por ITUARTE (1994), também ocorre com as demais espécies de Corbicula e mesmo com Cyanocyclas.

\section{Sphaeriidae Deshayes, 1855 (1820)

$$
\text { Euperinae Heard, } 1965
$$

\section{Eupera klappenbachi Mansur \& Veitenheimer, 1975.}

Fig. 25

Eupera klappenbachi Mansur \& Veitenheimer, 1975: 25.

Diagnose. Distingui-se pela forma discóide ou oval (altura 3,2 e comprimento $4 \mathrm{~mm}$ ); borda anterior curta e baixa, posterior alta e truncada; umbos arredondados e inflados, anteriores à metade do comprimento; presença de bisso relativamente delgado; perióstraco marrom-claro translúcido e finamente pregueado; internamente aparecem manchas (pontuações) negras ou violáceas levemente projetadas, distribuídas isoladamente ou agrupadas formando manchas maiores geralmente situadas na região distal dos umbos, que podem ser vistas por transparência fora da concha, principalmente em exemplares juvenis.

Material examinado. BrASIL, Rio Grande do Sul: Nova Santa Rita (ponte Tabaí-Canoas, no rio dos Sinos), 1 ex., 16.XII.2003, D. Pereira \& M.C.D Mansur leg. (MCP 8497).

Ocorrências ambientais. Vive fixa por fio de bisso, preferencialmente, em raízes de "aguapé-de-baraço", Eichhornia azurea (Sw.) Kunth, e mais raramente em outras macrófitas aquáticas marginais, que se adensam nos canais e margens das il has do delta do Jacuí e demais cursos inferiores de rios tributários da bacia do lago Guaíba (MANSUR et al. 1988, 1994, VolKMERRıBEIRo et al. 1984). É uma espécie abundante, não ultrapassando 7 a $8 \mathrm{~mm}$ de comprimento, amplamente distribuída nos rios e lagos da Bacia do Atlântico Sul.

\section{Sphaeriinae Baker, 1927 Pisidium globulus Clessin, 1888}

Fig. 26

Pisidium globulus Clessin, 1888: 173.

Diagnose. Distingue-se pela forma discóide ou oval; pequena (al tura 2,4 e comprimento $3 \mathrm{~mm}$ ), concha gl obosa ealta; região anterior pouco projetada e a posterior arredondada; umbos inflados, baixos e projetados acima da margem dorsal e deslocados para trás, posteriores à metade do comprimento; superfície brilhante de cor branca a amarelo muito pálido; al-

Revista Brasileira de Zoologia 23 (4): 1123-1147, dezembro 2006 

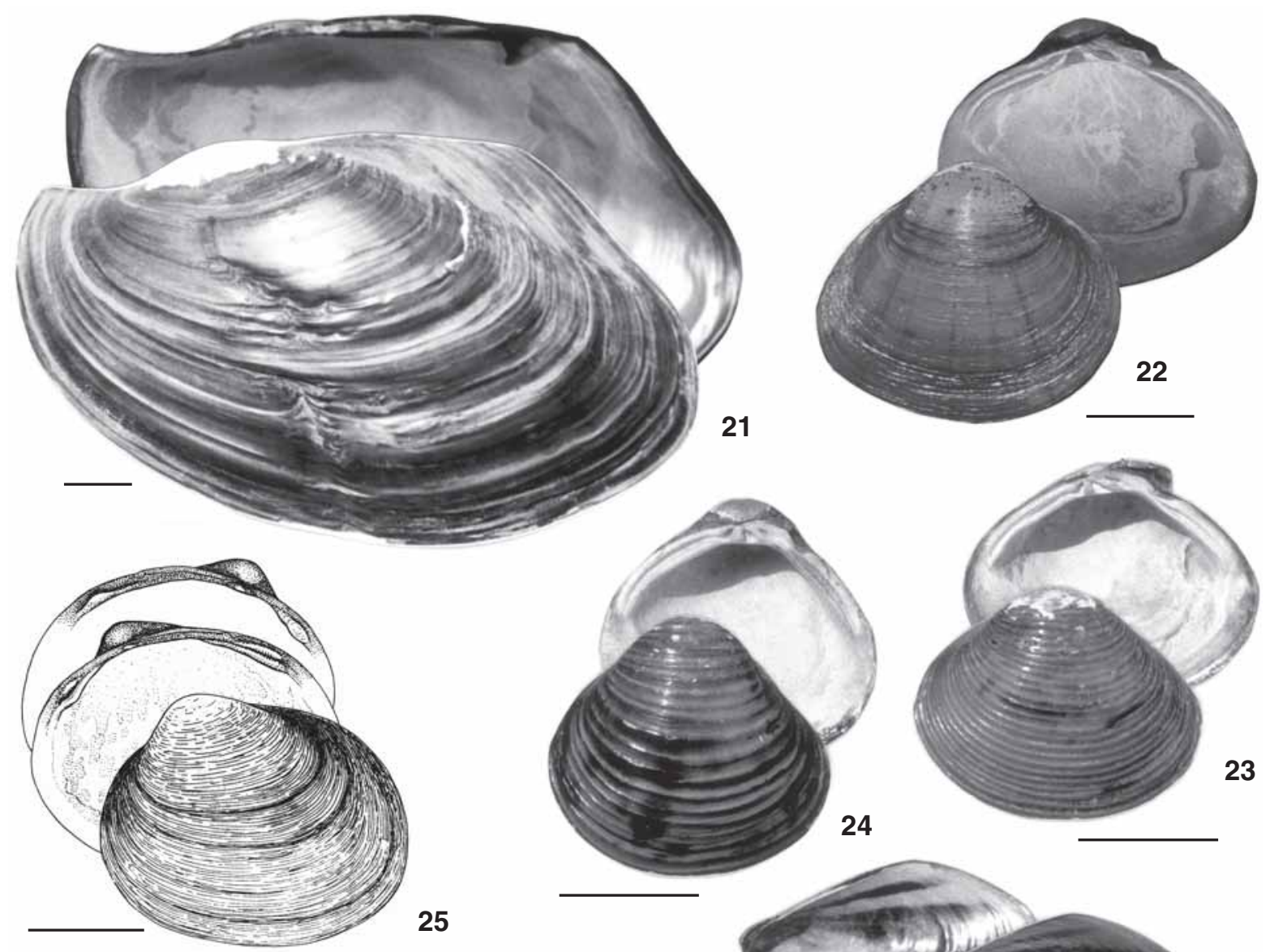

25

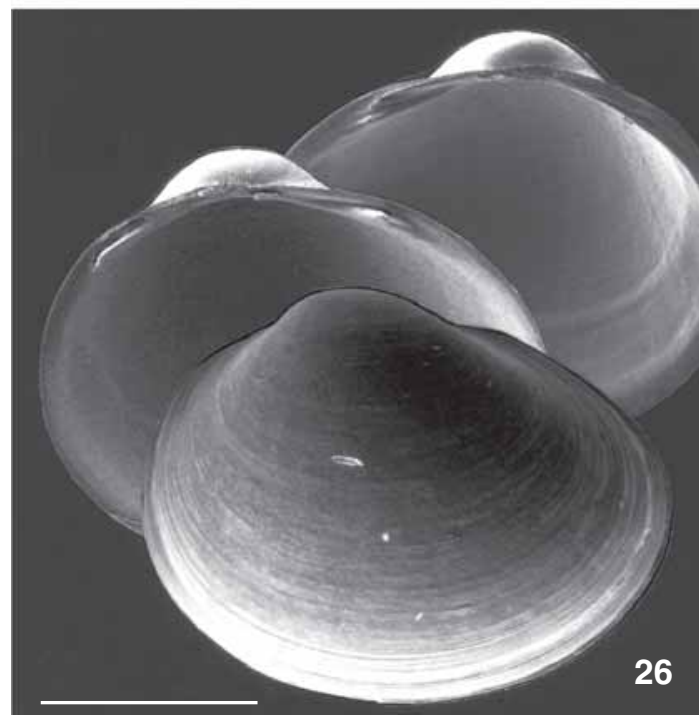

24

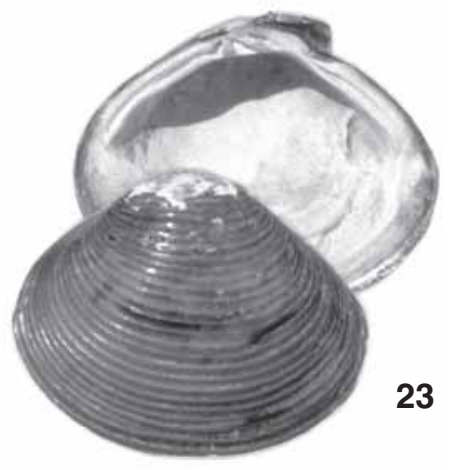

23

28

Figuras 21-28. (21) Mycetopodidae, vista interna da valva direita e vista externa da valva esquerda de Leila blainvilliana, escala $1 \mathrm{~cm}$; (22-24) Corbiculidae, vista interna da valva direita e vista externa da valva esquerda: (22) Cyanocyclas limosa; (23) Corbicula largillierti; (24) Corbicula fluminea, escala $1 \mathrm{~cm}$; (25-26) Sphaeriidae, vista interna das valvas direita e esquerda e vista externa da valva esquerda: (25) Eupera klappenbachi, escala 2 mm; (26) Pisidium globulus, escala 1 mm; (27-28) vista interna da valva direita e vista externa da valva esquerda: (27) Sphaeriidae, Pisidium sterkianum, escala 2 mm; (28) Mytilidae, Limnoperna fortunei, escala $1 \mathrm{~cm}$. 
gumas linhas concêntricas são mais escuras e demarcadas.

Material examinado. BrASIL, Rio Grande do Sul: "Taguara” (atual Taquara) S. Brasilien Ihering leg., 1 ex. identificado como “P. orbignyi Cl." (ZMHU 36506); Sapucaia do Sul (afluente do arroio José Joaquim, na Vila Vargas), 2 ex., 1991, D. Pereira leg. (MCP 8505). BRASIL, Rio Grande do Sul, rio Caí, arroio Maratá, 76 ex., XI.2001, M. Gallon leg. (MCP 8553).

Comentário. Tentou-se localizar o material-tipo no SMNS, onde foi depositada a coleção de S. Clessin, no entanto não foi encontrado. Em visita realizada em 1986 ao Museu de Berlim, pela autora sênior, foram encontrados quatro exemplares procedentes de Taguara (= atual município de Taquara) coletados por Ihering, com etiqueta mencionando o nome Pisidium orbignyi CL. seguido do nomeP. pulchellum ORB. Segundo CLESSIN (1879) o nome Cyclas pulchella Orbigny, 1835 era pré-ocupado pelo da espécie P. pulchellum Jenyns descrita para a Europa. Assim, um novo nome, Pisidium orbignyi Clessin, 1879, foi dado à espécie $P$. pulchella.

Após consulta ao curador da coleção de moluscos do ZMHU, Matthias Glaubrecht, em maio de 2004, soube-se tratar provavelmente do material tipo de Clessin, coletado por Ihering na localidade tipo de P. globulus e as medidas do exemplar maior conferirem com as da descrição original (altura 2,5 mm e comprimento $3 \mathrm{~mm}$ ). Segundo o Dr. Glaubrecht a etiqueta foi escrita por Eduard von Martens, curador daquela coleção até 1904.

Os exemplares examinados (altura 2,1 mm, comprimento $2,4 \mathrm{~mm}$ e diâmetro $1,7 \mathrm{~mm}$ ), oriundos um córrego tributário do arroio José Joaquim, afluente da margem esquerda do rio dos Sinos, em Sapucaia do Sul, são ligeiramente menores, mas apresentam proporções semel hantes àquelas oferecidas na descrição de P. globulus. Esta espécie também guarda algumas semel hanças e proporções com P. vile Pilsbry, 1897 (altura 2,4; comprimento 2,6 e diâmetro 2,0 mm), redescrita e ilustrada por ItUARTe (1995) e Mansur et al. (1991). Quando PILsbry (1897) descreveu P. vile não mencionou nem estabeleceu comparações com o material descrito por CLESSIN (1888). Deduz-se diante destes fatos, que, muito provavelmente, Pilsbry não teve acesso ao material, nem à obra mais recente de Clessin. PILSBRY (1897) apenas comentou e comparou as espécies descritas por ele com Pisidum orbignyi Clessin, 1879.

Após a descrição original, P. gl obulus foi citada apenas uma vez por HAAS (1959) quando o autor examinou material coletado em Nova Teutônia, no estado de Santa Catarina. Este material foi depositado no Museu de História Natural de Chicago.

\section{Pisidium sterkianum Pilsbry, 1897}

Fig. 27

Pisidium sterkianum Pilsbry, 1897: 291.

Diagnose. Distingue-se das demais espécies do gênero pela forma oval ou ovóide; tamanho avantajado (altura 4 e comprimento $6 \mathrm{~mm}$ ); região anterior bastante projetada e a posterior truncada e relativamente curta, geralmente formando um ângulo no encontro da margem dorsal com a posterior; umbos inflados, baixos, largos, não muito projetados acima da margem dorsal e deslocados para trás, posteriores a metade do comprimento; perióstraco amarelo-palha e finamente estriado.

Material examinado. BRASIL, Rio Grande do Sul: São Leopoldo, 2 exs + 1 v., 1909, Schupp leg. (MZUSP 2197); 27 vs +6 exs (MZUSP 963); 1 ex. (MZUSP 957).

Ocorrências ambientais. Em praia arenosa no rio Jacuí (MANSUR et al. 1988) e em margens com substrato constituído de silte, areia e cascalho, no arroio Capivara (Pereira et al. 2000, 2001).

Comentário. P. sterkianum (altura 5,0, comprimento 6,0 e diâmetro 3,8 mm) é a maior espécie do gênero na América do Sul (PILSBRY 1897). Durante o exame da coleção do MZUSP, foram encontrados vários lotes desta espécie identificados como Pisidium globulus Clessin, 1888, oriundos do município de São Leopoldo. Trata-se de material coletado posteriormente à descrição desta espécie, doado a $\mathrm{H}$. von Ihering na ocasião em que provavel mente ainda trabal hava no antigo Museu Paulista. Inicialmente pensou-se tratar da espécie descrita por Clessin, uma vez ser São Leopoldo muito próximo de Taquara (localidadetípica de P. globulus). Mas o material examinado (altura 4,8, comprimento 6,0 e diâmetro $3,4 \mathrm{~mm}$ ) não se enquadra nas medidas fornecidas por Clessin para P. globulus (comprimento 3,0; altura 2,5 e diâmetro $2,0 \mathrm{~mm}$ ) e sim nas medidas e características da espécie P. sterkianum (comprimento 6, altura 5 e diâmetro 3$8 \mathrm{~mm}$ ), que atinge o dobro do comprimento de P. globulus.

\section{Mytilidae Rafinesque, 1815 Mytilinae Rafinesque, 1815 Limnoperna fortunei (Dunker, 1857)}

Fig. 28

Diagnose. Concha triangular-retangulóide (mitilóide) e bissada (comprimento $3,8 \mathrm{~cm}$ ), perióstraco castanho-amarelado ou castanho-esverdeado, com manchas radiais violáceas.

Material examinado. BRAsil, Rio Grande do Sul, Canoas, Vila Rio Branco, arroio das Garças, estação de captação da CORSAN, 290 ex., 1.III.2004, M.C.D. Mansur, C.P. dos Santos, F. Cardoso leg. (MCP 8544); 43 ex. (MCP 8543); Porto Alegre, Belém Novo, Praia do Veludo (Associação de Pescadores), 2ex., 18.XII.2003, M.C.D. Mansur leg. (MCP 8551).

Ocorrências ambientais. Animal gregário que se fixa aos substratos endurecidos e firmes com auxílio de fio de bisso. Forma grandes aglomerações, especialmente sobre rizomas e raízes de plantas marginais fixas ou outros objetos firmes. Sua densidade é menor em plantas flutuantes ou semiflutuantes (MAnsur et al. 2003a).

Comentário. Espécie invasora originária do sudeste asiático, conhecida vulgarmente como mexilhão-dourado, foi registrada pela primeira vez no Brasil, junto ao delta do rio Jacuí, em novembro de 1998. No Guaíba, forma grandes aglomerados (> 140.000 ind./ $\mathrm{m}^{2}$ ), provocando alterações na estrutura da comunidade bentônica e da flora aquática. Danifica os cascos e moto-

Revista Brasileira de Zoologia 23 (4): 1123-1147, dezembro 2006 
res de embarcações e entope sistemas refrigeração de indústrias, encanamentos, filtros, bombas de recalque e adutoras que captam água bruta para abastecimento das cidades (MANSUR et al. 2003a). O material examinado provém do arroio das Garças, um tipo de canal, junto ao delta do Jacuí, que estabelece ligação entre a desembocadora do rio dos Sinos e do rio Gravataí (MANSUR et al. 2004b). Desde o ano de 2002, esta espécie vem provocando entupimentos das bombas e tubulações da captadora de água, junto a esse arroio, que pertence à Companhia Rio-Grandense de Saneamento (CORSAN), e que abastece as cidades de Canoas e Cachoerinha. Até 2004 esta espécie ocupava, no Rio Grande do Sul, uma área que abrange o baixo rio Jacuí, desde Santo Amaro no município de General Câmara, os cursos inferiores dos rios Taquari, Caí, Sinos e o Gravataí, até o extremo sul da Laguna dos Patos (MAnsur et al. 2004 a, b). Expedições recentes demostraram a ampliação da área de ocorrência, com registros no município de Rio Pardo, junto ao rio Jacuí, no Porto de Estrela, junto ao rio Taquari e mais ao sul, na localidade da Capilha (Taím) na lagoa Mírim. No rio dos Sinos sua ocorrência foi anunciada em periódicos locais (julho de 2006) para o município de Sapucaia do Sul.

\section{DISCUSSÃO}

Na bacia do rio dos Sinos foram constatadas 27 espécies de moluscos bivalves de água-doce: na zona superior ocorreram apenas duas espécies; na zona média, 11 espécies e na zona inferior, 24 espécies. A bacia do rio dos Sinos apresentou elevado número de espécies (riqueza) de bivalves nativos em relação aos levantamentos real izados anteriormente na bacia do Guaíba e em suas sub-bacias (Bonetto \& MAnsur 1970, MANSUR et al. 1988, 1994, Pereira et al. 2000).

Em levantamentos de espécies de bival ves límnicos Unionoida (Bonetto \& M ANSUR 1970, MANSUR et al. 1988, 1991, 1994, Pereira et al. 2000, 2001, Serrano et al. 1998), em bacias hidrográficas do Rio Grande do Sul e de outros estados, foram sentidas as mesmas dificuldades quanto à identificação taxonômica, devido à variabilidade intrapopulacional e a clinização.

Comentários sobre as dificuldades encontradas em relação à taxonomia do gênero Diplodon foram real izados por PARODIZ (1968, 1973). Ortmann (1921) considerou Diplodon um gênero composto por conchas e tipos mais ou menos indiferenciáveis enquanto os outros gêneros da ordem Unionoida apresentariam formas mais peculiares e marcantes.

Portanto, são necessárias algumas considerações sobre a diferenciação de espécies do gênero, como segue.

A identificação de gloquídios, desconhecidos até o momento para algumas espécies contribuiu para a melhor definição dos subgêneros e das espécies do gênero Diplodon ocorrentes na bacia do rio dos Sinos: subgênero Diplodon (gloquídios parasitos), D. (D.) aethipos, D. (D.) berthae, D. (D.) granosus multistratus, D. (D.) martensi, D. (D.) pilsbryi; subgênero Rhipidodonta (gloquídios não parasitos), D. (R.) hildae, D. (R.) koseritzi, D. (R.) charruanus e D. (R.) deceptus.
Devido falta de dados sobre larvas, diferentes autores apresentaram listas sinonímicas divergentes para as espécies de Diplodon. Para Ortmann (1921), constam na sinonímia de D. charruanus as espécies $D$. aethiops, D. hildae e D. berthae. As espécies D. aethiops, D. koseritzi, D. hildae e D. berthae foram consideradas sinônimos de Diplodon charruanus por HASS (1931) e BONETTO (1964). No entanto, os gloquídios de D. berthae e D. hildae são respectivamente dos tipos parasito de peixe e não parasito (Ortmann 1921, Mansur \& Silva 1999), ou seja, pertencem respectivamente aos subgêneros Diplodon e Rhipidodonta. O gloquídio de Diplodon charruanus é do tipo não parasito (M ANSUR \& Silva 1999). Além disso, D. berthae e D. hildae apresentam formas distintas da concha, elíptica-ovalada e oval respectivamente, sendo que na primeira se verifica internamente uma elevação oblíqua que sai da cavidade sub-umbonal até a região mediana da concha, seguida de uma depressão obliqua interna. Ape sar de D. charruanus apresentar gloquídio não parasito (M ANSUR \& Silva 1999) como D. hildae, difere de D. hildae também pela forma da concha e pelo dente pseudocardinal posterior, que é alto e crenulado. D. charruanus e D. pilsbryi foram diferenciados anatomicamente por MAnsur \& Anflor (1981). As duas espécies possuem forma elíptica-ovalado semelhante, mas diferem pela espessura da concha e pelo dente pseudocardinal posterior: concha robusta, com umbos altos e dente espesso com poucos dentículos radiais, em D. charruanus; concha frágil, umbos baixos e dente lamelar longo em D. pilsbryi. Existem também diferenças anatômicas no estômago, nos palpos labiais e no pé.

Diplodon martensi (elíptica-retangulóide) eD. pilsbry (elíptica-ovalada) foram considerados por HASs (1931) como sinônimos de $D$. ruachoicus (elíptica-ovalada). No entanto, a forma da concha, bem como o perióstraco ea dentição pseudocardinal, permitem considerar $D$. martensi e D. pilsbry como espécies distintas. D. pilsbry e D. ruachoicus são espécies muito afins, mas devido ao desconhecimento do gloquídio e das estruturas anatômicas internas de $D$. ruachoicus se torna injustificável uma sinonimização.

Os gêneros de Mycetopodidae apresentam uma melhor definição das espécies, o que facilita a identificação. Anodontites apresenta o maior número de espécies dentre os Mycetopodidae, mas estas apresentam menor variabilidade intrapopulacional quando comparadas às espécies do gênero Diplodon.

Os corbiculídeos exóticos foram introduzidos há mais de três décadas no lago Guaíba. Para a bacia do rio dos Sinos constatou-se que as duas espécies do gênero Corbicula foram registradas em áreas relativamente distintas: Corbicula largillierti foi provavelmente pioneira por se encontrar mais a montante, nas margens pedregosas do rio Paranhana, onde atualmente se destaca com maior densidade que os bivalves nativos; C. fluminea restringiu-se à zona inferior do rio dos Sinos.

Diante da escassez de dados morfológicos, morfométricos, de ilustrações na descrição orginal da espécie P. globulus e das incertezas que ainda pairam em relação ao material-tipo de Clessin, agora reencontrado em Berlim (ZMHU), sugere-se a 
revisão e resdescrição da espécie, a comparação com outras espécies afins e mapeamento de sua distribuição nas bacias hidrográficas.

Limnoperna fortunei, presente no delta do Jacuí desde 1998, ainda não colonizou a bacia rio dos Sinos. Dentre os fatores que provavelmente limitaram a sua distribuição cogitase: o fluxo incipiente de embarcações no rio dos Sinos, a escassez de substrato adequado (rochas e outros substratos duros) e provavelmente a poluição.

A elaboração da chave, das diagnoses e a redefinição da nomenclatura de formas da concha só foi possível pelo exame de vasto material de coleções científicas, inclusive material tipo. O reconhecimento e mapeamento da distribuição das espécies e suas formas, em cada bacia hidrográfica brasileira, permitindo a visualização dos padrões de variações morfológicas ao longo de gradientes geográficos e ecológicos, é necessária como complemento aos estudos larvais, anatômicos e genéticos com a finalidade de consolidar a taxonomia dos bivalves de água-doce.

Caracteres diagnósticos como a morfologia da larva e a escultura umbonal são primordiais para distinguir grupos e espécies de Diplodon. Porém, estes dados nem sempre estão disponíveis. As larvas são geralmente liberadas uma vez por ano, durante um período curto (geralmente na piracema). A observação da escultura fica restrita a disponibilidade de espécimes jovens, pois não se preserva nas conchas de adultos. Para meIhor definir os caracteres diagnósticos das espécies do gênero seria necessário o exame de um el evado número de exemplares em diversas fases de vida e várias populações para reconhecer a variabilidade intrapopulacional de cada espécie, em diferentes bacias hidrográficas e respectivas ecorregiões.

\section{CONCLUSÕES}

O número de espécies constatado na bacia do rio dos Sinos é superior aos números de espécies conhecidos em outras bacias gaúchas.

O número de espécies de bivalves límnicos foi mais elevado em direção à foz do rio dos Sinos.

Foram identificadas e figuradas, com base no material examinado, seis formas básicas da concha e sete formas derivadas, na bacia do rio dos Sinos, que permitiram a identificação das espécies, a elaboração da chave-dicotômica e das diagnoses.

São citações novas para a bacia do rio dos Sinos as seguintes espécies nativas: $D$. hildae, $D$. berthae, $D$. koseritzi, $M$. corrientesensis, Leila blainvilliana, E. klappenbachi eP. sterkianum.

As espécies exóticas, C. fluminea, C. largillierti eL. fortunei, são citadas pela primeira vez para a bacia do rio dos Sinos.

A localidade tipo de $A$. iheringi foi restringida para o rio Paranhana (2936'S e 5050'W ), no município de Igrejinha.

P. globulus foi citado e figurado pela primeira vez, no Rio Grande do Sul, depois da descrição original de CLESSIN (1888), quando examinou material enviado por Ihering procedente de Taguara (=atual município de Taquara, Rio Grande do Sul).

O gloquídio de D. aethiops foi observado pela primeira vez, como do tipo parasito de peixe.

O gloquídio de D. deceptus, observado pela primeira vez, é do tipo não parasito.

A diferenciação das espécies de Diplodon foi reforçada pela identificação dos subgêneros (Diplodon e Rhipidodonta), com base no conhecimento dos gloquídios.

\section{AGRADECIMENTOS}

Ao CNPq (Produtividade 302584/2002-1 eDCR FAPEMAT/ CNPq 35.0205/2004-3 NV). Ao DAAD pela concessão de bolsa especial de estágio ao autor sênior, que permitiu o exame das coleções científicas de moluscos em museus europeus. A Maria V. Petry (Museu de Zoologia, UNISINOS) e Ana M. Leal-Zanchet (Instituto de Pesquisas de Planárias, UNISINOS). A Tamara Falavigna pelo auxílio na curadoria. Felipe do C. Quadros (Museu de Ciência e Tecnologia, PUCRS), pela doação de material. Ao Marcelo Bischoff e Ismael Vargas Luz, pelo auxílio nas coletas realizadas no vale do rio Paranhana. Aos curadores das coleções científicas mencionadas pelo empréstimo de material, por facilitarem a visita às coleções científicas e especialmente a J.J. Parodiz (CM) e Mathias Glaubrecht (ZMHU) pelas pesquisas efetuadas em relação à busca do material tipo. A Bernadete Dedavid (Centro de Microscopia e Microanálise, PUCRS), pelo auxílio e fotografias ao MEV.

\section{REFERÊNCIAS BIBLIOGRÁFICAS}

BonetTo, A.A. 1961. Investigaciones a cerca de las formas larvales en el género Diplodon y su aplicación a los estudios sistemáticos. Santa Fé, Direccion General de Recursos Naturales, Ministerio de Agricultura e Ganaderia, 48p.

Bonetro, A.A. 1964. Espécies del género Diplodon en la pendiente atlántica del Sur del Brasil. Physis, Buenos Aires, 24: 323-328.

Bonetto, A.A. 1967. El gênero Anodontites Bruguière (Mollusca, Pelecypoda) en el sistema hidrográfico del Plata. Physis, Buenos Aires, 26 (73): 459-467.

Bonetto, A.A. \& I. Ezcurra. 1965. Notas malacológicas III: 5) La escultura del periostraco en el genero Anodontites. 6) El Lasidium de Anodontites trapezeus (SPIX). 7) El Lasidium de Mycetopoda siliquosa (SPIX). Physis, Buenos Aires, 25 (69): 197-204.

Bonetto, A. A. \& M.C.D. Mansur. 1970. Las nayades de la cuenca del Guaíba. Acta Zoologica Lilloana, Tucuman, 28: 241-260.

CalliL, C.T. \& M.C.D. Mansur. 2002. Corbiculidae in the Pantanal: history of invasion in southeast and central South America and biometrical data. Amazoniana, Kiel, 17 (1-2): 153-167.

Castellanos, Z.J.A. \& N.A. Landoni. 1990. La familia Mycetopodidae Gray, 1840 en la Republica Argentina, p. 1-86. In: R.A. Ringuelet (Ed.). Fauna de Agua Dulce de la Republica Argentina. Buenos Aires, FECIC, $86 \mathrm{p}$

CLESSIN, S. 1879. Familie der Cycladeen in Abbildungen nach der Natur mit Beschreibungen. In: F.H.W. MARTINI \& J.H. Chemnitz (Eds). Systematisches Conchylien Cabinet,

Revista Brasileira de Zoologia 23 (4): 1123-1147, dezembro 2006 
Nürnberg, 9 (3): 1-283.

Clessin, S. 1882. Neue Arten. Malakozoologische Blätter, Cassel, 5: 187-191..

Clessin, S. 1888. Binnenmollusken aus Südbrasilien. Malakozoologische Blätter, Cassel, 10: 165-174.

Comitesinos . 1990. Programa integrado de monitoramento da qualidade da água do rio dos Sinos e seus afluentes: utilização de um Índice de Qualidade da Água para o rio dos Sinos/RS. Porto Alegre, Comitê de Preservação, Gerenciamento e Pesquisa da Bacia do Rio dos Sinos, 43p.

Darrigran, G.A. 1991. Competencia entre dos especies de pelecípodos invasores. Corbicula fluminea (Muller, 1774) y C. largillierti (Philippi, 1844) em el litoral argentino del estuário del rio da la Plata. Biologia Acuática, La Plata, 15 (2): 214-215.

FeChTER, R. 1983. Das Typenmaterial von J. B. v. Spix in Brasilien gesammelten Unionacea. Spixiana, Munique, 9: 225-255.

FÉRUSSAC, A.E. DE. 1822. Tableaux systématiques des animaux mollusques. Paris, 111p.

FISCHER, P. 1890. Observations sur les genres Mycetopus et Solenaia. Journal Conchiliologie, Paris, 38: 5-14.

Focht, T. \& I.L. Veitenheimer-Mendes. 2001. Distribuição sazonal e reprodução de Neocorbicula limosa (Maton) (Bivalvia, Corbiculidae) no lago Guaíba, Rio Grande do Sul, Brasil. Revista Brasileira de Zoologia, Curitiba, 18 (1): 35-43.

Garces, L.M.M.P.; M.C.D. Mansur \& J.W. Thomé. 1989. Contribuição à conquiliometria de Neocorbicula limosa (Maton, 1811) (Bivalvia, Corbiculidae). Revista Brasileira de Zoologia, Curitiba, 6 (3): 507-516.

HAAS, F. 1930. Versuch einer kritischen Sichtung der Südamerikanischen Najaden, hauptsächlich an hand der Sammlung des Sencken berg-M useums I. Senckenbergiana, Frankfurt, 12 (4-5): 175-195.

HAAS, F. 1931a. Versuch einer kritischen Sichtung der Südamerikanischen Najaden, hauptsächlich an hand der Sammlung des Sencken berg-M useums II. Senckenbergiana, Frankfurt, 13 (1): 30-52.

HAAS, F. 1931b. Versuch einer kritischen Sichtung der Südamerikanischen Najaden, hauptsächlich an hand der Sammlung des Senckenberg-Museums III. Senckenbergiana, Frankfurt, 13 (2): 87-111.

HAAS, F. 1959. Inland Mollusksfrom Venezuela, Southern Breazil, and Peru. Fieldiana Zoology, Chicago, 39 (31): 363-371.

HAAS, F. 1969. Superfamilia Unionaceae, p. 1-663. In: R. MerTens; W. Hennig \& H. Wermuth (Eds). Das Tierreich. Eine Zusammenstellung und Kennzeichunung der rezenten Tierformen. Berlim, W. de Gruyter, vol. 88, 663p.

Hensel, R. 1867. Beiträge zur näheren Kenntniss der brasilianischen Provinz São Pedro do Rio Grande do Sul. Zeitschrift der Gesellschaft für Erdkunde zu Berlin, Berlim, 2 (10): 227-376.

IHERING, H.V. 1890. Revision der von Spix in Brasilien gesammelten Najaden. Archiv für Naturgeschichte, Berlim, 11 (2):
117-170.

IHERING, H.V. 1891. Anodonta und Glabaris. Zoologischer Anzeiger, Leipzig, 14: 477.

IHERING, H.V.1893. Najaden von S. Paulo und die geographische Verbreitung der süsswasser Faunen von Südamerika. Archiv für Naturgeschichte, Berlim, 1 (1/3): 45-140.

IHERING, H.V.1910. Über brasilianische Najaden. Abhandlungen der Senckenbergischen Naturforschenden Gesel Ischaft, Frankfurt, (32): 111-140.

IHERING, H.V. 1923. Especies argentinas del gênero Mycetopoda. Physis, Buenos Aires, 5 (19): 75-76.

ItUARTE, C.F. 1994. Corbicula and Neocorbicula (Bivalvia: Corbiculidae) in the Paraná, Uruguay, and Río de La Plata Basins. The Nautilus, Sanibel, 107 (4): 129-135.

ItUARTE, C.F. 1995. Nuevos registros de Pisidium Pfeiffer, 1821 y Sphaerium Scopoli, 1777 (Bivalvia: Sphaeriidae) en Chile, Bolivia y Noroeste argentino. Neotropica, La Plata, 41 (105106): 31-41.

KABAT, A.R. 1997. Correct family names for the fresh water MuteIoid bivalves (Unionoida: Etherioidea). Occasional Papers on Mollusks, Cambridge, 5 (72): 379-392.

KüsteR, H.C. 1856. Die Flussperlmuscheln (Unio et Hyria) in Abbildungen nach der Natur, p. 140-306. In: F.H.W. M ARTINI \& J.H. CHEMNITZ (Eds). Systematiches Conchylien-Cabinet. Nürnberg.

LAMARCK, J.B.P.A. 1819. Histoire Naturelle des Animaux sans Vertebres. Paris, Lamarck, vol. 6, no. 1, p. 66-89.

LEA, I. 1831. Observations on the Naiades. Transactions of the American Philosophical Society, Philadel phia 4: 63-121.

LEA, I. 1832-1874. Observations on the Genus Unio. Philadelphia, Janes Kay Jun, 13p.

LEA, I. 1834. Observations on the Naiades, and descriptions of new species of that, and other families. Transactions of the American Philosophical Society, Philadelphia, 5: 23-119.

LEA, I. 1856. Descriptions of twenty-five new species of exotic Unionidae. Proceedings of Academy Natural Science, Philadelphia, 8: 92-95.

LEA, I. 1860. Observations on the genus Unio, together with description of new species, their soft parts, and embryonic forms, in the family Unionidade. Journal of Academy Natural Science, Philadelphia, 7 (1): 1 -51.

Mansur, M..C.D. 1970. Lista de moluscos bivalves das famílias Hyriidae e Mycetopodidae para o Estado do Rio Grande do Sul. Iheringia, Série Zoologia, Porto Alegre, (39): 33-95.

Mansur, M.C.D. 1972. Morfologia do sistema digestivo de Castalia undosa martensi (Ihering, 1891) (Bivalvia, Hyriidae). Iheringia, Série Zoologia, Porto Alegre (41): 21-34.

MAnsuR, M.C.D. 1974. Monocondylaea minuana Orbigny, 1835: variabilidade da concha e morfologia do sistema digestivo (Bivalvia, Mycetopodidadae). Iheringia, Série Zoologia, Porto Alegre (45): 3-25.

Mansur, M.C.D. 1999. Gloquídio de Diplodon martensi (Ihering) (Mollusca, Bivalvia, Hyriidae) e seu ciclo parasitário. Revis-

Revista Brasileira de Zoologia 23 (4): 1123-1147, dezembro 2006 
ta Brasileira de Zoologia, Curitiba, 16 (2): 185-194.

Mansur, M.C.D. \& L.M. Anflor. 1981. Diferenças morfológicas entre Diplodon charruanus Orbigny, 1835 e Diplodon pilsbryi Marshall, 1928 (Bivalvia, Hyriidae). Iheringia, Série Zoologia, Porto Alegre, (60): 101-116.

Mansur, M.C.D. \& N.M.R. Campos-Velho 1990. Técnicas para o estudo de gloquídios de Hyriidae (Mollusca, Bivalvia, Unionoida). Acta Biologica Leopoldensia, São Leopoldo, 12 (1): 5-18.

Mansur, M.C.D. \& N.M.R. Campos-Velho. 2000. Glochidium of Castalia martensi (Ihering, 1891) (Mollusca, Bivalvia, Hyriidae). Heldia, Munique, 3 (1): 6-10.

Mansur, M.C.D. \& L.M.M.P. GARCES. 1988. Ocorrência e densidade de Corbicula fluminea (Müller, 1774) e Neocorbicula limosa (Maton, 1811) na Estação Ecológica do Taím, Rio Grande do Sul, Brasil. Iheringia série Zoologia, Porto Alegre, (68): 99-115.

ManSUR, M.C.D. \& J. OlAZARRI. 1995. Redescrição, distribuição e preferências ambientais de Anodontites ferrarisi (Orbigny, 1835) revalidada (Bivalvia). Iheringia, Série Zoologia, Porto Alegre, (79): 3-12.

Mansur, M.C.D. \& M.G.O. Silva. 1999. Description of glochidia of five species of freshwater mussels (Hyriidae: Unionoidea) from South America. Malacologia, Ann Arbor, 41 (2): 475-483.

Mansur, M.C.D. \& I.L. Veitenheimer 1975. Nova espécie de Eupera (Bivalvia: Sphaeriidae) e primei ras contribuições anatômicas para o gênero. Iheringia, Série Zoologia, Porto Alegre, (47): 23-46.

Mansur, M.C.D. \& I.L. Veitenheimer-Mendes. 1979. Redescrição de Mycetopoda legumen (Martens, 1988)-(Bivalvia, Mycetopodidae). Revista Brasileira de Biologia, Rio de Janeiro, 39 (3): 695-702.

Mansur, M.C.D.; C. Schulz \& L.M.M.P. GarCes. 1987. Moluscos bivalves de água doce: identificação dos gêneros do sul e leste do Brasil. Acta Biologica Leopoldensia, São Leopoldo, 9 (2): 181-202.

Mansur, M.C.D.; I.L. Veitenheimer-Mendes \& J.E.M. Almeida-Caon. 1988. Mollusca, Bivalvia de um trecho do curso inferior do rio Jacuí, RS, Brasil. Iheringia, Série Zoologia, Porto Alegre (67): 87-108.

Mansur, M.C.D.; C. Schulz; M.G.O. Silva \& N.M.R. Campos-VeLHo. 1991. Moluscos bivalves límnicos da Estação Ecológica do Taím e áreas adjacentes, Rio Grande do Sul, Brasil. Iheringia, Série Zoologia, Porto Alegre, (71): 43-58.

Mansur, M.C.D.; R.M. Valer \& N.C.M. Aıres. 1994. Distribuição e preferências ambientais dos moluscos bivalves do açude do Parque de Proteção Ambiental COPESUL, município de Triunfo, Rio Grande do Sul, Brasil. Biociências, Porto Alegre, 2 (1): 27-45.

Mansur, M.C.D; L.M.Z. RichinitTI \& C.P. SAntos. 1999. Limnoperna fortunei (Dunker, 1857), molusco bivalve invasor, na bacia do Guaíba, RS, Brasil. Biociências, Porto Alegre, 7 (2): 147-150.

Mansur, M.C.D.; C.P. Santos; G. Darrigran; I. Heydrich; C.T. Callil
\& F.R. CARdoso. 2003a. Primeiros dados quali-quantitativos do mexilhão dourado, Limnoperna fortunei (Dunker), no Delta do Jacuí, no Lago Guaíba e na Laguna dos Patos, Rio Grande do Sul, Brasil e alguns aspectos de sua invasão no ambiente. Revista Brasileira de Zoologia, Curitiba, 20 (1): 75-84.

Mansur, M.C.D.; I. Heydrich; D. Pereira; L.M.Z. RichinitTI; J.C. TARAsConi \& E.C. Rios. 2003b. Moluscos, p. 49-71. In: C.S. Fontana; G.A. Bencke \& R.E. Reis (Eds). Livro vermelho da fauna ameaçada de extinção no Rio Grande do Sul. Porto Alegre, EDIPUCRS.

Mansur, M.C.D.; C.B. Quevedo; C.P. Santos \& C.T. Callil. 2004a. Prováveis vias da introdução de Limnoperna fortunei (Dunker,1857) (Mollusca, Bivalvia, Mytilidae) na bacia da laguna dos Patos, Rio Grande do Sul e novos registros de invasão no Brasil pelas bacias do Paraná e Paraguai, p. 3338. In: J.S.V. SILVA \& R.C.C.L. SouZA. (Eds). Água de lastro e Bioinvasão. Rio de Janeiro, Interciências.

Mansur, M.C.D.; F.R. Cardoso; L.A. Ribeiro; C.P. Santos; B.M. Thormann; F.C. Fernandes \& L.M.Z. RichinitTI. 2004b. Distribuição e conseqüências após cinco anos da invasão do mexilhão-dourado, Limnoperna fortunei, no estado do Rio Grande do Sul, Brasil (Mollusca, Bivalvia, Mytilidae). Biociências, Porto Alegre, 12 (2): 165-172.

MARTENS, E.V. 1868. Über südbrasilianische Land und Süsswassermollusken. Nach der Sammlung von Dr. R. Hensel. Malakozoologische Blätter, Cassel, 15: 169-217.

MARTENS, E.V. 1888. Zeige endlich noch zwei neue SchnekenArten aus der südbrasilianischen Provinz Rio-Grande vor, welche ihm von Hern, v. Heimburg in Oldenburg zur Bestimmung augeschikt wurden und deren kurze Beschreibung hier folgt. Sitzungsberichte Gesellschaft Naturforschender Freunde zu Berlin, Berlim, 7: 64-65.

Martins, D.S.; I.L. Veitenheimer-Mendes \& M.C. Faccioni-Heuser. 2004. Corbicula (Bivalvia, Corbiculidae) em simpatria no lago Guaíba, RS, Brasil. Biociências, Porto Alegre, 12 (2): 129-138.

MARSHALL, W.B. 1927. New species of the mollusks of the genus Corbicula from Uruguay and Brazil. Proceedings of the United States National Museum, Washington, 72 (17): 1-7.

MARSHALL, W.B. 1928. New fresh-water and marinebivalve shells from Brazil and Uruguay. Proceedings of the United States National Museum, Washington, 74 (17): 1-7.

Maton, W.G. 1811. Description of seven species of Testacea. Transactions of the Linnean Society, London, 10 (13): 325332.

ModelL, H. 1942. Das natürliche System der Najaden. Senckenbergiana, Frankfurt, 74 (5-6): 51-55, 161-191.

MorRetes, F.L. 1949. Ensaio de catálago dos moluscos do Brasil. Arquivos do Museu Paranaense, Curitiba 7: 3-216.

MüLLER, O.F. VON. 1774. Vermium Terrestrium et Fluviatilum, seu Animalium, Infusorium, Helminthocorum, et Testaceocorum, non Sarinorum, Succincta Historia. Havniae and Lipsiae, Heineck and Faber, vol. 2, 214p. 
Ortmann, A.E. 1921. South American naiades; a contribution to the knowledge of the freshwater mussels of South America. Mememoirs of the Carnegie Museum, Pittsburgh, 8 (3): 451-670.

ORBIGNY, A.D'. 1835. Synopsis terrestrium et fluviatilium molluscorum in suo per American Meridionalem itinere. Magazin de Zoologie, Paris, 5: 1-40.

PARodIZ, J.J. 1968. Annotaded catalogue of the genus Diplodon (Unionacea -Hiriidae). Sterkiana, (30): 1-22.

PARodiz, J.J. 1973. The species complex of Diplodon delodontus (Lamarck) (Unionacea, Hyriidae). Malacologia, Ann Arbor, 14: 247-270.

PARodiz, J.J. 1996. The taxa of fossil Mollusca introduced by Hermannnn von Ihering. Annals of Carnegie Museum, Pittsburgh, 65 (3): 183-296.

Parodiz, J.J. \& L. Hennings. 1965. The Neocorbicula (Mollusca, Pelecypoda) of the Paraná-Uruguay Basin. Annals Carnegie Museum, Pittsburgh, 38 (3): 69-96.

Pereira, D.; I.L. Veitenheimer-Mendes; M.C.D. Mansur \& M.C.P. Silva. 2000. Malacofauna límnica do sistema de irrigação do arroio Capivara e áreas adjacentes, Triunfo, RS, Brasil. Biociências, Porto Alegre, 8 (1): 137-157.

Pereira, D.; L.A. Inda; J.M. Consoni \& H.G. Konrad. 2001. Composição e abundância de espécies de moluscos do bentos marginal da microbacia do arroio Capivara, Triunfo, RS, Brasil. Biociências, Porto Alegre, 9 (1): 3-19.

PHILIPPI, R.A. 1844. Descriptiones testaceorum quorundam novorum, maximechinensis. Zeitschrift für Malakozoologie, Hannover, 1844: 161-167.

PHILIPPI, R.A. 1847. Cyrena Lamarck, p. 75-79. In: Abbildungen und Beschreibungen neuer oder wenig gekannter Conchylien. Cassel, Theodor Fischer Verlag.

PIlsbry, H.A. 1897. New species of mollusks from Uruguay. Proceedings of the Academy of Natural Sciences of Philadelphia, Philadel phia, 49: 290-298.

Prashad, B. 1929. Revision of the Asiatic species of the genus Corbicula. III - The species of the genus Corbicula from China, south-eastern Russia, Tibet, Formosa and thePhilippinelslands. Memoirs of the Indian Museum, Calcutta, 9: 49-72.

RıcCl, C.N. 1990. Gloquídios de Diplodon Spix, 1827: D. (D.) multistriatus (Lea, 1831) (Mollusca, Bivalvia, Hyriidae). BoIetim do Museu Nacional, Rio de Janeiro, (344): 1-10.

Serrano, M.A.S.; R.S. TietbÖHL \& M.C.D. Mansur. 1998. Sobre a ocorrência de moluscos Bivalvia no Pantanal de Mato Grosso, Brasil. Biociências, Porto Alegre, 6 (1): 131-144.

Simone, L.R.L. 1994. Anatomical characters and sytematics of
Anodontites trapesialis (Lamarck, 1819) from South America (Mollusca, Bivalvia, Unionoida, Muteloidea). Studies Neotropical Fauna and Environment, Lisse, 29 (3): 169-185.

SIMPSON, C.T. 1900. Sinopsis of the naiades or pearly freshwater mussels. Proceedings of the United States National Museum, Washington, 22 (1205): 501-1044.

SIMPSON, C.T. 1914. A descritive catalogue of the naiades or pearly freshwater mussels. Michigan, Bryant Walker, 1540p.

SoWERBY, G.T. 1868. Monograph of the genus Mycetopus. In: L.A. ReEve (Ed.). Conchologia Iconica. London, L. Reeve, vol. 17.

SPIX, J.B. \& J.A. W AGNER. 1827. Testacea fluviatilia quae in itenere per Brasiliensia ani MDCCCXVII - MDCCCXX collegit et pigenda curavit Dr. J.B. Spix, digerri descripsit et observationibus illustravit D.J.A. Wagner. München, Schrank \& Martius, 36p.

$V_{A Z}$, J.F. 1986. Hermannnn von Ihering. Boletim Informativo da Sociedade Brasileira de Malacologia, São Paulo, (60): 13-15.

Veitenheimer-Mendes, I.L. 1973a. Contribuição ao estudo do gênero Leila Gray, 1840 (Mycetopodidae-Bivalvia). Iheringia, Série Zoologia, Porto Alegre, (42): 64-89.

Veitenheimer-Mendes, I.L. 1973b. Anodontites Bruguière, 1792 no Guaíba-RS(Bivalvia: Mycetopodidae) I. Anodontites trapesialis forbesianus (Lea, 1860). Iheringia, Série Zoologia, Porto Alegre, (44): 32-49.

Veitenheimer-Mendes, I.L. 1981. Corbicula manilensis (Philippi, 1844), molusco asiático, na bacia do rio Jacuí e do Guaíba, RS, Brasil (Bivalvia, Corbiculidae). Iheringia, Série Zoologia, Porto Alegre, (60): 63-74.

Veitenheimer-Mendes, I.L. \& M.C.D. Mansur. 1978a. Morfologia, histologia e ecologia de Mycetopoda legumen (Martens, 1988) - (Bivalvia, Mycetopodidae). Iheringia, Série Zoologia, Porto Alegre (52): 33-71.

Veitenheimer-Mendes, I.L. \& M.C.D. Mansur. 1978b. Mycetopoda legumen (Martens, 1988): Iasídio e desenvolvimento parasitário (Bivalvia, Mycetopodidae). Revista Brasileira de Biologia, Rio de Janeiro, 38 (3): 531-536.

Volkmer-Ribeiro, C.; B.M. Moraes; R. Rosa-Barbosa; M.C.D M ansur \& I.L. Veitenheimer-Mendes. 1984. Um estudo do bentos em raízes de Eichhornia azurea (Sw.) Kunth, do curso inferior de um rio subtropical sul-americano. Revista Brasileira de Biologia, Rio de Janeiro 44 (2): 125-132.

ZANARDINI, I.F. 1965. Nota sobre Diplodon eAnodontites (Mollusca, Pelecypoda) de rios de Curitiba (Paraná). Boletim Instituto de Defesa do Patrimônio Natural, Curitiba, (6): 1-11.

Recebido em 01.IV.2005; aceito em 01.XI.2006.

Revista Brasileira de Zoologia 23 (4): 1123-1147, dezembro 2006 